\title{
A review of research and recent trends in analysis of composite plates
}

\author{
PRAVIN KULKARNI*i), ASHWINKUMAR DHOBLE and PRAMOD PADOLE
}

Department of Mechanical Engineering, Visvesvaraya National Institute of Technology, Nagpur 440 010, India

e-mail: pravin.kul@gmail.com; ashwin.dhoble@mec.vnit.ac.in; pmpadole@ rediffmail.com

MS received 18 April 2017; revised 7 December 2017; accepted 1 February 2018; published online 7 June 2018

\begin{abstract}
The use of advance composite materials is increasing in various industrial applications such as renewable energy, transportation, medical devices, etc. As the demand for stability under high mechanical, thermal, electrical and combined loads is increasing, research is being focused on developing newer types of composites and developing analytical and numerical methods to study composite plates as well. The present work is aimed to provide a comprehensive review of research in the structural analysis of composite plates along-with research trends in the last 15 years. The article first presents the evolution of plate theories comparing their formulations, applicability and discusses some key papers, results and conclusions. Evolution of research from the equivalent shear deformation theories (ESL) such as first order theory and higher order theories based on various shape strain functions e.g., polynomial, trigonometric to layer-wise, zigzag and displacement potential theories is presented. The comparative analysis of various solution approaches is done based on a review of research work in the structural analysis of plates. This is followed by review of meshless analysis methods for composite materials highlighting problem domains where conventional finite element analysis (FEA) approach has limitations. This article also presents a discussion on the new methods of plate analysis such as region-by-region modeling, hierarchic modeling and mixed FE and neural network based modeling. An attempt has been done in this article to focus on research trends in the last 15 years.
\end{abstract}

Keywords. Composite plate theories; shear deformation; FGM; meshless methods; region-by-region modeling.

\section{Introduction}

The usage of composite materials in the structural applications such as aerospace, wind energy is increasing. Various structural members such as rotors, wings and beams are made of composite materials. Composites provide better strength-to-weight ratio and better stiffness-to-weight ratio and superior damage tolerance compared to conventional metals. They also offer excellent resistance to corrosion and chemical attack apart from manufacturability into complex geometrical shapes. The increasing demand for sustainable and renewable energy such as wind power as seen in Global Wind Energy Report 2016 [1] and the need for economical methods of transportation is contributing to increasing use of composites and smart structures in automotive and aerospace applications as per Diodati et al [2]. The study of composite materials, applications and the structural analysis has always been the focus area of researchers. The present article first introduces the types of Equivalent Single Layer (ESL) theories followed by details of the evolution of the plate theories. Various plate theories are analyzed with comparison based

*For correspondence on assumptions and considerations, applicability, analysis approaches and various research areas in recent focus are discussed. Research papers in the last five years are discussed in more details to analyze the research trends such as thermos-mechanical analysis, buckling and free vibrations, fracture and delamination. The article also analyzes the research in the newer areas such as functionally graded plates, mesh-free approximations and stochastic methods such as neural network for plate analysis.

\section{Current status of knowledge and results for composite plate theories}

The Equivalent Single Layer theories (ESL) can be broadly classified into 3 types such as the Classical Laminate Plate Theory (CLPT), First Order Shear Deformation Theory (FSDT) and Higher Order Shear Deformation Theories (HSDT). Their relative comparison is given in table 1.

Thus it is seen that the applicability and flexibility of the plate theories to address real nature of boundary conditions have increased over time. The newer theories are also richer, more accurate and can account for through-thickness transverse stress variations better. 
Table 1. Comparison of various equivalent single layer (ESL) theories.

\begin{tabular}{|c|c|c|c|}
\hline Theory & Details & $\begin{array}{l}\text { Transverse shear and normal deformation } \\
\text { consideration }\end{array}$ & Applicability \\
\hline CLPT & $\begin{array}{l}\text { Based on Kirchhoff's plate theory. Does not } \\
\text { satisfy stress free boundary condition }[3,4]\end{array}$ & $\begin{array}{l}\text { Not considered. Violates stress free boundary } \\
\text { conditions }(\mathrm{BC}) \text { at top, bottom surfaces }\end{array}$ & Thin plates \\
\hline FSDT & $\begin{array}{l}\text { Based on Reissner [5], Mindlin [6], Whitney and } \\
\text { Pagano [7] plate theories. Uses shear correction } \\
\text { factor to satisfy BC }[8,9]\end{array}$ & $\begin{array}{l}\text { Constant variation of transverse shear. Neglects } \\
\text { cross sectional warping and no stress free BC }\end{array}$ & $\begin{array}{l}\text { Moderately thick } \\
\text { plates }\end{array}$ \\
\hline HSDT1 & $\begin{array}{l}\text { Uses polynomial shear strain function. Satisfies } \\
\text { stress free boundary condition }[10-12]\end{array}$ & $\begin{array}{c}\text { Realistic variation of transverse shear, includes } \\
\text { cross-section warping. Stress free BC } \\
\text { considered }\end{array}$ & $\begin{array}{l}\text { Thin and Thick } \\
\text { plates, shells, beams }\end{array}$ \\
\hline HSDT2 & $\begin{array}{l}\text { Uses Trigonometric shear strain function. Theory } \\
\text { is richer than polynomial functions, simple, } \\
\text { more accurate and the stress free surface } \\
\text { boundary conditions can be guaranteed } \text { a priori } \\
\text { [13] }\end{array}$ & Provides stress free BC at top, bottom surfaces & \\
\hline HSDT3 & $\begin{array}{l}\text { Uses Exponential shear strain function. Theory is } \\
\text { very important for cantilevers as per Carrera } \\
\text { et al [14] and predicts critical buckling and } \\
\text { bending stress close to exact solution }[15,16] \text {. } \\
\text { Satisfies stress free boundary condition }\end{array}$ & $\begin{array}{l}\text { Considered with parabolic distribution of the } \\
\text { transverse shear strains [9]. Provides stress free } \\
\text { BC at top, bottom surfaces }\end{array}$ & \\
\hline
\end{tabular}

\section{Evolution of plate and shell theories}

\subsection{Shear deformation theories}

Pagano [17] developed 3D elastic solution for bidirectional laminates with pinned edges under static bending. Reddy [18], Touratier [19] and Soldatos [20] further extended it by proposing the shear deformation theories for various material and loading conditions. Reddy's theory for orthotropic laminate shells accounts for parabolic distribution of the transverse shear strains through thickness and tangential stress-free boundary conditions. Touratier's approach compared the results by Reddy [9] and accounted for cosine shear stress distribution, warping throughout the thickness of the plate during rotation and stress-free top and bottom plate surfaces. The theory was validated by investigating various problems such as bending, free undamped vibration and buckling of a three-layered (sandwich and laminated), symmetric cross-ply, rectangular or square plate simply supported along all edges, etc. Soldatos proposed a general two-dimensional theory suitable for the static and/or dynamic analysis of a transverse shear deformable plate, constructed of a homogeneous, monoclinic, linearly elastic material and subjected to any type of shear tractions at its lateral planes. Lu and Liu [21] developed a theory to calculate the interlaminar shear stress which accounted for both the interlaminar shear stress continuity and the transverse shear deformation. The authors compared their results with classical analysis by Pagano [17]. Lee and Liu [22] developed a multi-layer theory to find out the classical analytical solution for the interlaminar stresses in both thin and thick composite laminates using higher order shape function. The theory can help calculate interlaminar stresses directly from the constitutive equations instead of using the 3D equilibrium equations. The authors compared their results with classical analysis by Pagano [17] and also used FEM technique to validate the results. Becker [23] analyzed symmetric crossply laminate for closed form solution using higher order plate theory. The conventional analysis for laminates assumed the composite interface to be rigidly bonded. Hence in further development Becker et al [24] analyzed the phenomenon of localized high interlaminar stresses in the vicinity of a free rectangular corner of a rectangular cross-ply laminate with symmetrical lay-up under thermal loading. Mantari et al [25] proposed a new shear deformation theory for sandwich and composite plates. In this paper the displacement of the middle surface is expanded as a combination of trigonometric and exponential functions of the thickness coordinate and the transverse displacement is considered to be constant through the thickness. The theory accounts for adequate distribution of the transverse shear strains through the plate thickness and tangential stress-free boundary conditions on the plate boundary surface, therefore a shear correction factor is not required. For the laminate geometry shown in figure 1 , the displacement field is defined as,

$$
\begin{gathered}
\bar{u}(x, y, z)=u(x, y)-z \frac{\partial w}{\partial x}+f(z) \theta_{1}(\mathrm{x}, \mathrm{y}) \\
\bar{v}(x, y, z)=v(x, y)-z \frac{\partial w}{\partial x}+f(z) \theta_{2}(\mathrm{x}, \mathrm{y}) \\
\bar{w}(x, y, z)=w
\end{gathered}
$$

Function $f(z)=c\left(\sin \left(\frac{\pi z}{h}\right) e^{m \cos \left(\frac{\pi z}{h}\right)}+y z\right), \quad m \geq 0$,

$$
y=\frac{\pi m}{h}, \quad c=1
$$



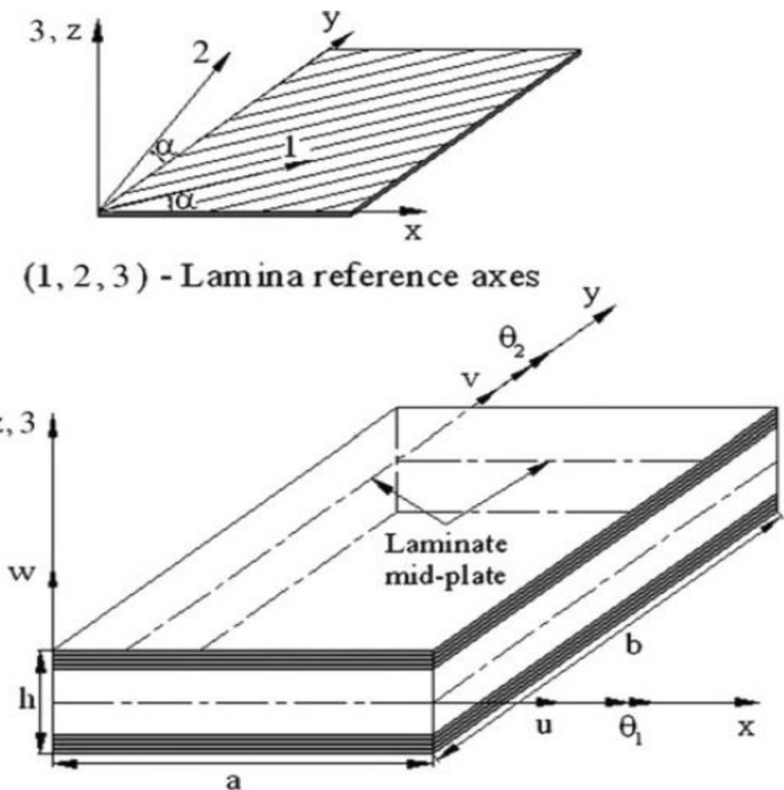

$(\mathrm{x}, \mathrm{y}, \mathrm{z})$ - Laminate reference axes

Figure 1. Laminate geometry with positive set of lamina/laminate reference axes, displacement components and fiber orientation [13].

Here $\mathrm{u}(\mathrm{x}, \mathrm{y}), \mathrm{v}(\mathrm{x}, \mathrm{y}), \mathrm{w}(\mathrm{x}, \mathrm{y}), \theta 1(\mathrm{x}, \mathrm{y})$ and $\theta 2(\mathrm{x}, \mathrm{y})$ are the five unknown functions of middle surface of the plate as given in figure 1 , while $f(z)$ represents the shape functions for the distribution of the transverse shear strains and stresses along the thickness.

The results of the present theory obtained by Navier-type solution approach are in close agreement with the 3D elasticity by Aydogdu [26] and other HSDTs such as by Touratier [19] and Reddy and Liu [27] for the shape function parameter of 0.1 . The model as per authors performs better than all the existing higher order shear deformation theories for analyzing the static behavior of multilayered sandwich and composite plates. Schwab [28] developed a unique displacement field which addresses both bending and in-plane membrane loadings. He developed a-posteriori modeling error estimators for hierarchical models of homogeneous elastic plates of monoclinic materials and showed the effectives of the model even for thick anisotropic plates and general edge conditions (table 2).

Alipour [37] developed a new analytical approach for bending and stress analysis of angle-ply laminated composite and sandwich plates. The unique part is that for the first time a system of three second order coupled partial differential equations were solved using power-series solution. The results of the numerical examples proved that the solution is generic to be applied for cross/angle-ply laminated composite and sandwich plates with various combinations of the edge conditions, even for moderately thick plates, orientation angle of the laminated composite plate, arbitrary non-uniform transversely distributed loads and non-uniform elastic foundation.
Recently, Thai and Choi [38] have for the first time developed Levy's solution of RPT for isotropic plates. The thick rectangular plates have 2 opposite edges simply supported and 2 under arbitrary boundary conditions and was analyzed for static, buckling and free vibration cases. Similarly, Thai and Kim [39, 40] applied Levy's solution for orthotropic plates under buckling and free vibrations, respectively. Wanji and Zhen [41] have done a review of the recent developments of displacement based laminate plate theories. They classified the theories in 3 categories. (i) global displacement theories (GDT) obtained by expanding the displacement components as Taylor's series in terms of the thickness coordinate [7, 42, 43], (ii) improved global displacement theory (IGDT) as authors call it, which can be obtained by adding a zigzag-shaped $\mathrm{C}^{0}$ function to in-plane displacement components of arbitrary global displacement theories [44-48], (iii) zig-zag theory (ZZT) which can be constructed by superimposing linear zig-zag field to the global displacement field [49-53]. The authors point out that by imposing both continuity of transverse shear stresses at interfaces and free surface conditions, the number of unknowns in this model becomes independent of the number of layers and (iv) global-local displacement theories (GLDT) [54-57] based on double superposition hypothesis proposed by $\mathrm{Li}$ and Liu [58]. The authors solved various numerical examples to verify and compare the displacement theories. A snapshot of the displacement and stress results are shown in figure 2 and some notes on the theories are in table 3.

Their results show that the global-local theories such as FGLT-50 and TGLT-30 are more accurate in comparison to other theories. Also for higher order theories such as HSDT98, the results approach close to exact solution. However the $3^{\text {rd }}$ order theories (HSDT-33 and HSDT-R) as well as the first order theory (FSDT) are less accurate. As for the in-plane stresses, the refined displacement theories (FGLT-50, TGLT30 and ZZTC) are more accurate than other theories.

Some important conclusions drawn by the authors are as under.

(a) The global-local theories are more suitable for prediction of transverse shear stresses directly from constitutive equations in comparison with other theories. (b) The zig-zag theories satisfying the interlaminar continuity of transverse shear stresses are still unable to accurately predict transverse shear stresses directly from constitutive equations, in which $3 \mathrm{D}$ equilibrium equations have to be adopted in order to obtain satisfactory transverse shear stresses. (c) Even if 3D equilibrium equations were adopted, Reddy's higher order shear deformation theory [9] as well as first-order theory (FSDT) is still unable to accurately compute transverse shear stresses of both moderately thick and thick laminated plates. To obtain satisfactory transverse shear stresses, the global displacement theories with very higher order shear deformation should be adopted. (d) Among all the 2D displacement theories, only both the global-local higher-order theories and the zig-zag theories seemingly satisfy transverse shear stress continuity at 
Table 2. A snapshot of research articles for the shape strain functions along with an overview of analysis, applicability and the conclusions.

\begin{tabular}{|c|c|c|c|c|}
\hline Research & Shape functions & Applicability & Analysis approach & Conclusions from paper \\
\hline $\begin{array}{l}\text { Ambartsumian } \\
\text { [29] }\end{array}$ & $f(z)=\frac{z}{2}\left[\frac{h^{2}}{4}-\frac{z^{2}}{3}\right]$ & $\begin{array}{c}\text { Thick and thin } \\
\text { laminate plates, } \\
\text { shells }\end{array}$ & & \\
\hline Reissner [5] & $f(z)=\frac{5 z}{4}\left[1-\frac{4 z^{2}}{3 h^{2}}\right]$ & $\begin{array}{l}\text { Thick and thin } \\
\text { laminate plates, } \\
\text { shells }\end{array}$ & $\begin{array}{c}\text { Assumes constant transverse } \\
\text { shear through the entire } \\
\text { thickness }\end{array}$ & \\
\hline Reddy [9] & $f(z)=z\left[1-\frac{4 z^{2}}{3 h^{2}}\right]$ & $\begin{array}{l}\text { Thick and thin } \\
\text { laminate plates }\end{array}$ & $\begin{array}{l}\text { Variational consistent } \\
\text { equilibrium equations are } \\
\text { developed. Exact closed- } \\
\text { form solutions of } \\
\text { symmetric cross-ply } \\
\text { laminates obtained }\end{array}$ & $\begin{array}{l}\text { Same no. of dependent } \\
\text { unknowns as in the FSDT, } \\
\text { but accounts for parabolic } \\
\text { distribution of the } \\
\text { transverse shear strains } \\
\text { through the plate thickness } \\
\text { and has better results than } \\
\text { FSDT }\end{array}$ \\
\hline Touratier [19] & $f(z)=\frac{h}{\pi} \operatorname{Sin}\left(\frac{\pi z}{h}\right)$ & $\begin{array}{l}\text { Thick to thin } \\
\text { laminate and } \\
\text { sandwich plates }\end{array}$ & $\begin{array}{l}\text { Static and dynamic analysis } \\
\text { for free, forced bending, } \\
\text { frequency and buckling of } \\
\text { simply supported plates }\end{array}$ & $\begin{array}{c}\text { The theory has same order of } \\
\text { complexity as the FSDT, } \\
\text { but does not use shear } \\
\text { correction factors and yet } \\
\text { more efficient than FSDT }\end{array}$ \\
\hline Soldatos [20] & $f(z)=h \operatorname{Sinh}\left(\frac{z}{h}\right)-z \cosh \left(\frac{1}{2}\right)$ & $\begin{array}{l}\text { Homogeneous } \\
\text { monoclinic, } \\
\text { specially } \\
\text { orthotropic } \\
\text { plates }\end{array}$ & $\begin{array}{l}\text { Static analysis of laminate } \\
\text { plates based on } 5 \text { degrees } \\
\text { of freedom (DOF) } \\
\text { symmetric shear } \\
\text { deformation theory }\end{array}$ & $\begin{array}{c}\text { For thin plates, the theory is } \\
\text { efficient in analyzing } \\
\text { displacement and stress } \\
\text { through plate thickness. } \\
\text { Can account for through- } \\
\text { thickness displacement } \\
\text { variation choices }\end{array}$ \\
\hline Aydogdu [26] & $\begin{array}{c}f(z)=e^{-2\left(\frac{z}{h}\right)^{2}} \text { or } f(z)=z \alpha^{-\frac{\left(\frac{z}{h}\right)^{2}}{\ln \alpha}} \\
\alpha=3\end{array}$ & $\begin{array}{l}\text { Laminated } \\
\text { composite } \\
\text { plates and beam }\end{array}$ & $\begin{array}{l}\text { Static and dynamic analysis } \\
\text { covering free, forced (sine } \\
\text { load), frequency and } \\
\text { buckling analysis of } \\
\text { simply supported beam }\end{array}$ & $\begin{array}{c}\text { Better results compared to } \\
\text { other } 5 \text { DOF shear } \\
\text { deformation theories like } \\
\text { Khdeir and Librescu [11] } \\
\text { and Reddy and Liu [27]. } \\
\text { Vibration and buckling } \\
\text { results are within 2\% } \\
\text { accuracy and stress results } \\
\text { except shear stress are } \\
\text { within 8\% accuracy with } \\
\text { 3D solution }\end{array}$ \\
\hline $\begin{array}{c}\text { Mantari et al } \\
{[30,25]}\end{array}$ & $\begin{array}{c}f(z)=z m\left(-2\left(\frac{z}{h}\right)^{2}\right)+y z \\
\mathrm{~m}=2.85, \mathrm{y}=0 \\
f(z)=c\left(\sin \left(\pi \frac{z}{h}\right) e^{\left(m \cos \left(\pi \frac{z}{h}\right)\right)}+y z\right) \\
m=0.5, y=\frac{\pi}{2 h}, c=1\end{array}$ & $\begin{array}{l}\text { Thick, thin, } \\
\text { shallow and } \\
\text { deep } \\
\text { multilayered } \\
\text { sandwich and } \\
\text { composite } \\
\text { plates and } \\
\text { shells }\end{array}$ & $\begin{array}{l}\text { Navier type closed form. } \\
\text { Static, dynamic analysis } \\
\text { using bi-sinusoidal, } \\
\text { distributed and localized } \\
\text { loads for cylindrical and } \\
\text { spherical shells and plates }\end{array}$ & $\begin{array}{c}\text { The theory performs close to } \\
\text { or in some cases better } \\
\text { than other HSDTs like } \\
\text { Reddy and Liu [27], } \\
\text { Srinivas [31], Song, et al } \\
\text { [32], Ferreira et al [33], } \\
\text { Karama et al [34] yet } \\
\text { being simple (same no of } \\
\text { dependent unknowns as } \\
\text { FSDT) }\end{array}$ \\
\hline $\begin{array}{l}\text { Shimpi [35] for } \\
\text { isotropic, } \\
\text { Shimpi and } \\
\text { Patel [36] } \\
\text { for } \\
\text { orthotropic }\end{array}$ & $f(z)=\frac{5}{4}\left[1-\frac{4 z^{2}}{h^{2}}\right]$ & $\begin{array}{c}\text { Orthotropic plates } \\
\text { and shells }\end{array}$ & $\begin{array}{l}\text { Static and free vibration } \\
\text { analysis of SS rectangular } \\
\text { plates under UDL using } \\
\text { analytical approach }\end{array}$ & $\begin{array}{l}\text { A refined plate theory (RPT) } \\
\text { with only } 2 \text { unknown } \\
\text { functions, no coupling for } \\
\text { static and only inertial } \\
\text { coupling for dynamic } \\
\text { analysis. Variationally } \\
\text { consistent }\end{array}$ \\
\hline
\end{tabular}




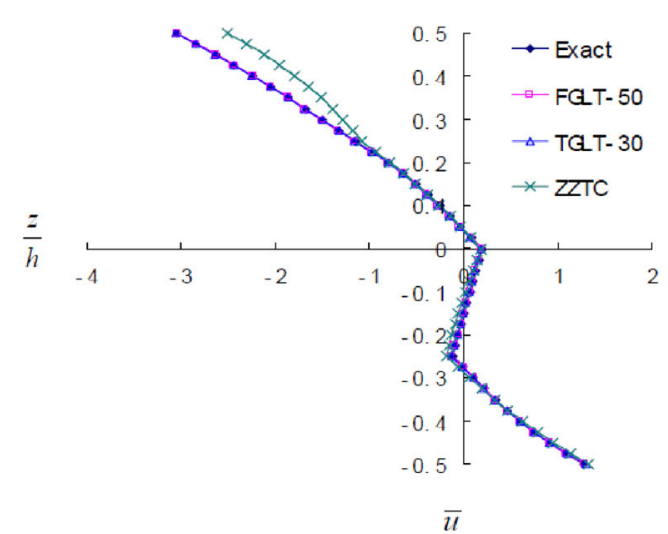

(a) In-plane displacement

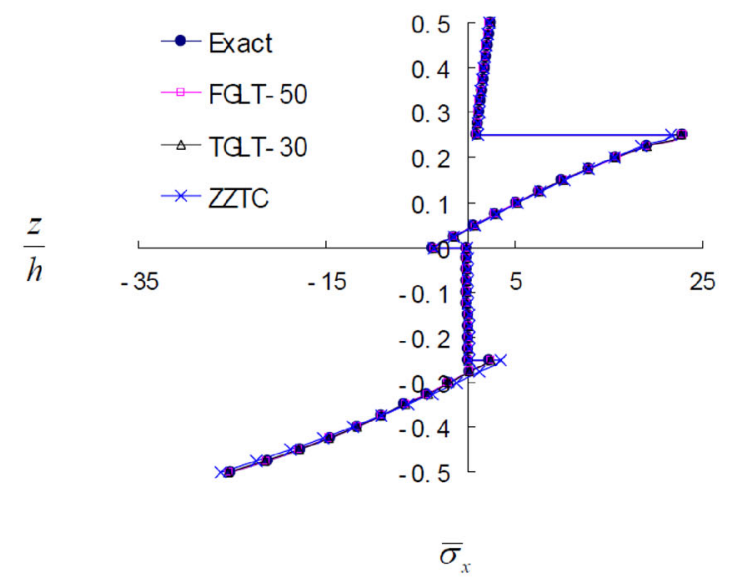

(b) In-plane stress

Figure 2. (a) Distribution of in-plane displacement (u) and (b) in-plane stress ( $\sigma \mathrm{x})$ obtained from refined displacement theories through thickness direction of four-layer plate $(\mathrm{a} / \mathrm{h}=4)$.

interfaces, but neglecting the continuity condition of transverse normal stresses at interfaces.

Many researchers have developed the hierarchical plate models which like classical analytical methods, provide dimension reduction technique to convert $3 \mathrm{D}$ problem into simpler 2D models that asymptotically converges to the exact, 3D solution, regardless of relative sizes of the thickness and heterogeneities. Szabo and Sharmann [63] have formulated hierarchical sequence of FE models based on principle of virtual work that be applied to beams, plates, arches and shells with focus on numerical implementation of generalized solution. Their approach does not apriori fix the discretization parameters for transverse displacement variation. Their work proposes orderly sequence of discretization unlike conventional theories for these problems. One of the parameters $p$ represents the polynomial degree of basis function for mid surface and the other parameter $q$ is mapped transversely to middle surface in standard coordinate system. Their FE solution converges to exact 3D solution as parameters $p$ and $q \rightarrow \infty$. Babuska et al [64] discussed the governing principles behind formulation of hierarchic models for laminates composites and proposed that the exact solutions corresponding to the hierarchic sequence of models converge to the exact solution of the corresponding problem of elasticity for a fixed laminate thickness, and the exact solution of each model converges to the same limit as the exact solution of the corresponding problem of elasticity with respect to the laminate thickness approaching zero. Actis et al [65] proposed shell models which are dimensional reduction of full 3D elastic models in which the admissible displacements in the transverse direction are constrained. These family of models satisfy the conditions of approximability, asymptotic consistency and optimality of the convergence rate to ensure optimizing modeling errors. These conditions are explained by below equations.

$$
\begin{gathered}
\lim _{i \rightarrow \infty}\left(u_{E X}^{(3 D)}-u_{E X}^{(H M \mid i)}\right) E(\Omega)=0 \\
\lim _{h \rightarrow 0}\left(\frac{\left(u_{E X}^{(3 D)}-u_{E X}^{(H M \mid i)}\right) E(\Omega)}{\left(u_{E X}^{(3 D)}\right) E(\Omega)}\right)=0 \\
\frac{\left(u_{E X}^{(3 D)}-u_{E X}^{(H M \mid i)}\right) E(\Omega)}{\left(u_{E X}^{(3 D)}\right) E(\Omega)} \approx C h^{\gamma_{i}}
\end{gathered}
$$

As $\mathrm{h} \rightarrow 0$ and $\mathrm{i} \rightarrow \infty$ with convergence rates $\gamma_{i+1}>\gamma_{i}$ where $u_{E X}^{(3 D)}$ and $u_{E X}^{(H M \mid i)}$ are the exact $3 \mathrm{D}$ and hierarchical solutions, respectively for the space $E(\Omega)$ and $\mathrm{h}$ is the total plate thickness. The authors presented plate and shell examples in which the hierarchic family of finite element spaces based on p-extension were used which properly utilized the design finite element meshes, to control discretization errors as well.

\subsection{Layer-wise and zig-zag theories}

The layer-wise theories have evolved due to a need to predict local deformations accurately which higher order theories do not predict as they satisfy only displacement continuity. Srinivas [31] developed a multilayer laminated plates, but it did not satisfy the continuity of interlaminar traction. Layer-wise theories consider independent degrees of freedom for each layer and ensure smooth transition of displacement and stresses at layer interfaces.

Ahmed and Basu [66] developed p-element based FE model based on higher order theory for $2 \mathrm{D}$ analysis of general bending and cylindrical bending of thin-to-thick laminated composite plates.

Murakami [44] used Reissner's variational principle to add layer-wise zig-zag functions to the FSDT for local 
Table 3. Notes on some of the theories used by Wanji and Zen [41].

\begin{tabular}{lc}
$\begin{array}{l}\text { Theory } \\
\text { code }\end{array}$ & \multicolumn{1}{c}{ Reference } \\
\hline Exact & $\begin{array}{r}\text { Three-dimensional elasticity solutions based on the } \\
\text { Pagano's method [59] }\end{array}$ \\
FGLT-50 & $\begin{array}{r}\text { Analytical results based on the fifth-order global-local } \\
\text { theory [60] }\end{array}$ \\
TGLT-30 & $\begin{array}{r}\text { Analytical results based on the third-order global-local } \\
\text { theory discarding transverse normal strain }\end{array}$
\end{tabular}

HSDT-54 Analytical results based on the global higher order theory by Matsunaga [61]

IGDT-M Analytical results based on the improved global displacement theory proposed by Murakami [44]

HSDT-98 Analytical results based on the global higher order theory HSDT-98 proposed by Matsunaga

HSDT-33 Analytical results based on the global higher order theory HSDT-33 proposed by Kant and Swaminathan [62]

HSDT-R Analytical results based on the global higher order theory HSDT-R proposed by Reddy [9]
Exact solution for cylindrical bending for laminates with arbitrary number of orthotropic/isotropic layers and sandwich plates

A fifth-order global-local theory proposed for multilayered plates (>6 layers)

Third order global-local theory that satisfied displacement and transverse shear stresses continuity conditions at interfaces.

Governing equations have 11 unknowns which are independent of the number of layers

A global higher-order plate theory with 17 unknown variables in displacement field developed for cross-ply laminated composite and sandwich plates subjected to lateral pressure

A 13 unknown theory which automatically satisfy the zig-zag shaped variation of in-plane displacement along thickness direction. It does not a priori satisfy continuity conditions of transverse shear stresses at interfaces

In-plane displacement field consists of $9^{\text {th }}$-order polynomial in global thickness direction and the transverse deflection is represented by an $8^{\text {th }}$-order polynomial of global thickness direction

In-plane and transverse displacement fields of HSDT-33 consist of third-order polynomial in thickness direction

Third order shear deformation theory proposed by Reddy [9] with 5 unknowns and having transverse shear stress free boundary conditions deformation consideration. Sciuva [45] derived general linear equations governing the motion of moderately thick multilayered anisotropic shells with an a priori assumed displacement field which is piece-wise linear in the $\mathrm{u}$ and $\mathrm{v}$ components and fulfills the static and geometric continuity conditions between the contiguous layers. It also takes into account the distortion of the deformed normal. Shear and rotatory inertia terms have also been considered in the formulation. Reddy [67] developed a generalized laminate plate theory which is used as a basis for many displacement based 2D theories. Mitchell and Reddy [68] developed a hybrid approach for multilayered smart skin piezoelectric structures in which a 3rd order Reddy ESL is used for the mechanical displacement field, whereas the potential function for piezoelectric laminae is modeled using a layerwise discretization in the thickness direction.

Researchers have been focusing on mixed mode modeling of plates to overcome some of the accuracy problems of these theories especially when dealing with discontinuities, generic plate shapes or for solving problems of higher order dynamic vibrations [69-71]. Angioni et al [72] employed multiple plate theories simultaneously as an alternative to costly full scale 3D FEM solution. Their approach based on (eXtended Finite Element Method) XFEM uses less accurate plate model for global analysis for gross displacement calculations and is enhanced by more accurate and complex plate model in each laminate sub-region where transverse stressstrain analysis is required to predict damage initiation. Aslami and Akimov [73] developed a multilevel method for local static analysis of plates by combining FEM and discrete wavelet transform (FEM-DWT) methods. They proposed that the process of transforming governing equations to localized form and applying reduction and averaging algorithm helped to reduce the size of the unknowns in governing equations and simplified the solution while having good accuracy as compared to FEM solution. Their approach is very suitable for localized loads and plates with localized properties. Zhang and Cheng [74] have developed a wavelet-decomposed Rayleigh-Ritz model for high frequency analysis of $2 \mathrm{D}$ plates for free and forced vibrations. Their mixed approach solution combining flexibility of 2D Daubechies wavelet method and versatility of Rayleigh-Ritz method offers accuracy with ability to reach very high number of modes (roughly fifteen thousand). Going further, Geng et al [75] addressed the limitation of the wavelet finite element methods (WFEMs) having their applicability only in the low frequency domain for dynamic analysis of thin plates. They proposed a wavelet multi-elements method based on $\mathrm{C} 1$ type B-spline Kirchhoff plate (C1BKP) element (having 81 nodes and 121 DOFs) with a novel assembly algorithm for these elements. They carried out numerical studies for various types of plate boundary conditions and observed 
that the relative error with analytical solution is under $0.004 \%$ for up to 1000 modes as well. Their method can also be combined with commercial FEM solution to address complex problem spaces.

Since most of the plate theories are used to obtain global response such as buckling load, Mohite and Upadhyay [76] studied the quality of the point-wise stresses obtained using higher-order shear deformable, hierarchic and layer-wise theories for a plate under transverse loading. Their study identified the effectiveness of higher order, layer-wise theories and hierarchical models in various problem types. They concluded that HSDT and hierarchical models are effective only for thin plates for point-wise displacements due to significant shear deformation effects in thick plates causing piece-wise higher order polynomial behavior of the exact solution whereas layer-wise models provide accurate state of stress for all plate thicknesses. Further, they showed that the use of adaptive mesh refinement is critical for accuracy of computed local stresses to the exact solution and also for lowering critical failure loads by as much as $40 \%$. This is because the load computation errors are due to boundary layer, locking effect and discretization errors which are addressed by mesh adaptivity.

Recently, Theofanis and Saravanos [77] defined a higherorder layer-wise theory for thick composite and sandwich composite plates. The theory considers quadratic and cubic polynomial distributions for the in-plane displacements, in addition to the linear approximations assumed by linear layer-wise theories. A Ritz-type exact solution is developed to study the structural response of thick composite and sandwich composite plates. The advantage of their approach is that it needs lesser number of discrete layers compared to linear layer-wise theories to model the thick composite laminate through-thickness and in the prediction of interlaminar shear stresses at the interface. Maturi et al [78] developed a layer-wise shear deformation theory within the framework of collocation with radial basis function to analyze natural frequencies, displacements and stresses of sandwich plates. The authors have implemented the formulation using Carrera's Unified Formulation [CUF]. Their results for sandwich plates show that layerwise approach should be used instead of ESL theories for soft-core sandwich plates where the skin properties are much higher than core. In order to balance the cost of computation due to higher order terms of CUF and result accuracy, axiomatic/asymptotic models have been developed which evaluates the relevance/impact of each higher order term in the governing equation. Mashat et al [79] evaluated Layer-wise and ESL theories by means of axiomatic-asymptotic approach. They developed a reduced model by representing the higher order displacement terms using CUF while preserving the accuracy of the full model. The authors noted that (a) the reduced models depends on geometrical and material properties (e.g., a/h, Ef/Ec). (b) Accurate stress and displacement trends can be derived applying asymptotic/axiomatic method along with correct error criteria and the best criteria is problem dependent.

Recently Cinefra et al [80] extended the axiomaticasymptotic technique of refined mechanical, thermal and piezoelectric plate theories (ESL as well as Layer-wise) to detect the best terms of governing equation (for Navier type closed form) so as to obtain lowest error with respect to a reference solution. The goal of this formulation is to develop Best Theory Diagram (BTD) for multifield problems for the simply supported laminated plates. The BTD provides a correlation between the number of terms of a model with reference solution. BTDs are generated using a generic algorithm and Carrera Unified Formulation (CUF). This study highlighted the influence of type of load, geometry, material parameters and displacement/stress components on BTD definition.

Mohite and Upadhyay [81] used a novel approach of effectively combining equivalent through-thickness and single layer formulation for any order of thickness of plate models thereby reducing the cost and yet increasing the accuracy of computation of local stresses, strains and displacements. The approach has been shown to be effective in unsymmetrical laminae, cut-outs, local deformations, corner edges and sudden change of boundary conditions and material. They employed region-by-region modeling scheme in which enriched approximation (Layer-wise or Intermediate models with sub-laminae if desired) is used only in the vicinity of the "hot-spots" of local deformity, while in the rest of the domain, a lower order model is defined. Some of the findings of the authors were that (a) layer-wise, intermediate and equivalent models fail in the case of singular vertices, singular edges and material transitions and so layer-wise models need to be augmented locally by using graded sub-layers, along with a geometrically graded in-plane mesh. (b) The approach of Layerwise model in one-layer neighborhood of region of interest and a low order equivalent model outside the region can greatly reduce computational cost and (c) the significant 3D effects in the area of singularities and discontinuities where solution is non-smooth can be solved with local resolution using layer-wise model, along with graded sub-layers in the vicinity. An example of the region-by-region modeling is shown in figure 3.

For example, the LM3332 model indicates the Layerwise transverse functions for displacements at the order of $p_{x y}=3, p_{z}^{1}=p_{z}^{2}=3, p_{z}^{3}=2$ where $p_{z}^{i}=$ transverse function in $\mathrm{z}$ direction and $p_{x y}=$ in-plane transfer function and the displacements are given by Eq. (8).

$$
u_{j}(x, y, z)=\sum_{i=1}^{n j} u_{j i}(x, y) \bar{M}_{i}(z)
$$

where $\mathrm{j}=1 . .3, \mathrm{n} 1=\mathrm{n} 2$ and $\mathrm{n} 3$ dependent on order of approximation $p_{z}^{1}=p_{z}^{2}, p_{z}^{3}$ number of layers. $\bar{M}_{i}(z)$ is the family of $1 \mathrm{D}$ hierarchic basis functions. 
(a)

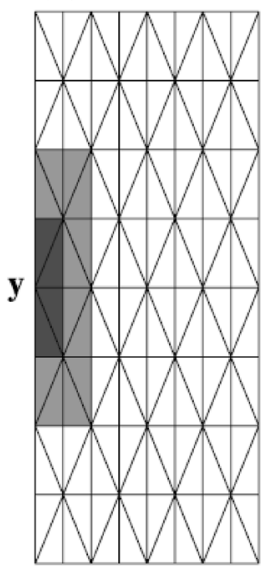

$\mathbf{X}$ (b)

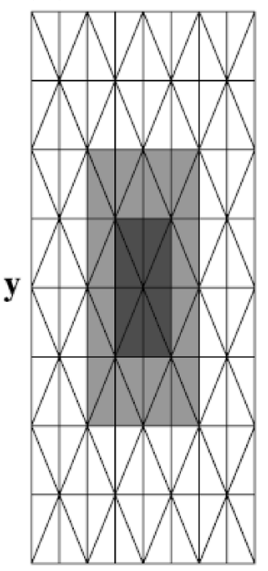

$\mathbf{X}$ (c)

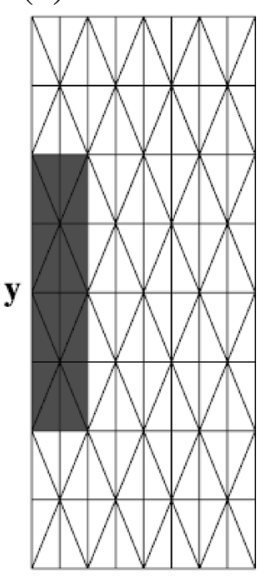

$\mathbf{x}$

Figure 3. Region-by-region schemes for transverse shear and inplane stress for [165/-165] and [150/-150/150] laminate. (a) RRI: with LM3332 in the dark shaded region, LM3112 in the grey shaded region and EQ3112 in the rest, (b) RR-II: with LM3332 in the dark shaded region, LM3112 in the grey shaded region and EQ3112 in the rest and (c) RR-III: with LM3332 in the dark shaded region and EQ3112 in the rest [81].

Saeedi et al [82] carried out research to propose an efficient and accurate alternative to the computationally expensive 3D finite element method for analyzing delaminated multilayered plates under uniaxial extension. The authors extend the layer-wise stress model, called the LS1 model, to delaminated multilayered plates subjected to uniaxial extension. Comparison with FEM shows good agreement except near singularities such as free edges, crack tips, etc. Hence authors have proposed a refinement approach [83], called the refined LS1, and applied to angleply rectangular composite laminates. The comparison between the refined LS1 and 3D-FE models shows good agreement in terms of interlaminar stresses and strain energy release rate, even very close to singularities. Hence the authors conclude that the refined LS1 model can be used as an accurate and very efficient model for the prediction of initiation and propagation of delamination in multilayered plates under uniaxial extension using stress based or energy release rate based criteria. The authors recently extended the analysis [84] to cylindrical bending loading cases and found good agreement with FE results for the classical mode I (Double Cantilever) and mode II (End Notched Flexure) delamination as well.

Sahoo and Singh [85] proposed a new trigonometric zigzag shear deformation theory (ZZTSF) for the laminated composite and sandwich plates. Their theory is based on shear strain shape function assuming non-linear distribution of transverse shear stresses. The theory satisfies inter-laminar stress continuity at the layer interfaces as well as the condition of zero transverse shear stresses at the top and bottom surfaces of the plates. The simplicity of the theory

lies in having the same (5) number of unknowns as FSDT and having the number of unknowns independent of the number of layers. This makes the computational efforts much less than the higher order theories. They studied free vibration and stability analysis of laminated composite and sandwich plates with different modular ratio, aspect ratio, span to thickness ratio, loading and boundary conditions, ply orientations, lay-up number and Eigen modes, etc. As per authors, this theory can be called as the most efficient for the free vibration and stability analysis due to closeness with 3D results, less number of elements, wide applicability and minimum computational efforts. Recently, Theofanis and Papadopoulos [86] presented coupled higher-order layer-wise piezoelectric laminate mechanics applicable to composite and sandwich plates under static load and/or electric voltages. They analyzed the local through-thickness response by using a gross through-thickness discretization and also studied the effects of transverse compressibility and ply angle on the local through-thickness response. Moleiro et al [87] have assessed layer-wise mixed models using least-squares formulation for the coupled electromechanical static analysis of multilayered plates. They evaluated two layer-wise mixed least-squares models having different sets of independent variables among displacements, in-plane strains, transverse stresses, electric potential, in-plane electric field components and transverse electric displacement, etc. required for fulfilling interlaminar $\mathrm{C}^{0}$ continuity a priori. The new model developed by authors needs less number of independent variables (displacements, transverse stresses, electric potential and transverse electric displacement) for continuity which they validated by doing static electromechanical analysis of multilayered plates with different aspect ratios. Their new model also performs well when compared with 3D exact solution.

Thus it is seen that the layer-wise and zigzag formulation of plate models have been used by researchers to include the through thickness displacement slope variations and transverse shear and normal stress continuity while maintaining accuracy with 3D solutions. The usage of reduced models based on axiomatic/asymptotic models is helping to balance the computation cost and result accuracy.

\subsection{Displacement potential theories}

Traditionally the solution of the elastic problems have been tried with stress function approach [88]. But in practical situations the structural elements have mixed-mode boundary conditions where stress and displacements are required to be considered. The stress function approach based modeling cannot address such situations as it accepts boundary conditions only in terms of stress components [89].

The displacement formulation consists of finding two displacement functions simultaneously from the two 
second-order elliptic partial differential equations of equilibrium. This approach was proved to address plane stress and plane strain problems of arbitrary shaped elastic bodies with mixed boundary conditions as pointed out by Akanda et al [90]. In the recent times, displacement potential based boundary modeling approach for shells has gained momentum. This approach was first proposed by Deb Nath [91] for the solution of two-dimensional elasticity problems of an orthotropic composite lamina. Prominent researchers in this area have studied the displacement potential based approach extensively for solving the elastic problems of isotropic and orthotropic elements analytically [92-97] and numerically $[98,99]$. The approach consists of defining two displacement parameters associated with the two-dimensional elasticity problems in terms of a single displacement potential function such that one of the equilibrium equations is satisfied automatically. This reduces the problem to the solution of a single fourth-order partial differential equation, which is solved in terms of Fourier series. An example of the potential function $\psi$ is shown below in Eqs. (9)-(10)

$$
\begin{gathered}
u_{x}=\frac{\delta^{2} \psi}{\delta x \delta y} \\
u_{y}=-\frac{A_{11}}{A_{12}+A_{66}} \frac{\delta^{2} \psi}{\delta x^{2}}-\frac{A_{66}}{A_{12}+A_{66}} \frac{\delta^{2} \psi}{\delta y^{2}}
\end{gathered}
$$

Here $A_{11}, A_{12}$ and $A_{66}$ are the constants based on material elasticity and ply thickness. The resultant equilibrium equation is shown in Eq. (11) and the solution in the form of Fourier series is in Eq. (12)

$$
\begin{gathered}
\frac{\delta^{4} \psi}{\delta x^{4}}+\left[\frac{A_{22}}{A_{66}}-\frac{A_{12}^{2}}{A_{11} A_{66}}-2 \frac{A_{12}}{A_{11}}\right] \frac{\delta^{4} \psi}{\delta x^{2} \delta y^{2}}+\frac{A_{22}}{A_{11}} \frac{\delta^{4} \psi}{\delta y^{4}}=0 \\
\psi(x, y)=\sum_{m=1}^{\infty} X_{m}(x) \cos \alpha y+M x^{3}
\end{gathered}
$$

Nath and Ahmed [93] analyzed the elastic behavior of an orthotropic composite panel cantilever subjected to end moment and shear loading. They employed finite difference computational scheme, based on the displacement potential formulation. They analyzed the effects of aspect ratio, panel reinforcements and edge stiffening on static response. They found that the results are more reliable and accurate then FEM at the regions of transient boundary conditions and also their approach takes less computation efforts.

\section{Functionally graded materials}

Functionally graded materials (FGM) are the advanced composite materials made of two or more constituent phases which have a continuous and smooth variation of composition and material properties such as elasticity moduli, density and Poisson's ratio in preferred directions. These aspects provide lot of advantages to FGM over conventional homogeneous materials in terms of optimization of material properties. The research in FGM is also increasing to cater to needs of wide engineering applications. Koizumi [100] proposed the concept of functionally graded materials (FGM). The fundamentals of FGMs along with detail literature review was given by Suresh and Mortensesn [101]. FGMs have material properties of its constituents varying according to a function of position along certain dimension(s). They maximize the performance of its constituent materials such as heat and corrosion resistance of ceramics on one side, and mechanical strength and toughness of metals on the other side of a body. The continuous change in the microstructure of FGM provide many advantages over fibre-reinforced laminated composite materials, such as lesser probability of debonding at high thermal loading. Additionally, fibre-reinforced composite materials have problems of residual stresses due to the difference in coefficients of thermal expansion of the fiber and matrix in the composite materials and crack development at the interface region. These problems are greatly reduced in FGMs due to gradually varying volume fractions.

While there has been a lot of research in the early years on FGM, the applicability of shear deformation theories to FGMs was proposed by Praveen and Reddy [102] using FSDT including the von Karman nonlinear effects. Their theory accounted for the transverse shear strains, rotary inertia and twisting of FG plates. This is one of the earliest and widely used studies on FG plates in the field of structural and thermal loading. Reddy [103] extended the formulation of Praveen and Reddy to third order shear deformation theory for Navier solution and also presented nonlinear static and dynamic FEM results based on first order theory. His formulation accounted for the thermomechanical coupling, time dependency, and von Karman-type geometric non-linearity. The results showed that the gradients in material properties play an important role in determining the response of the FGM plates. There has been a lot of research in the coupled thermos-elastic, buckling and vibration analysis of FG plates. A brief note on some of these is shown in table 4.

Jha et al [114] have recently done a critical review of the research in functionally graded plates in the area of thermoelastic static, vibration and stability analyses since 1998 . The researchers point out that while the exact solutions of simply supported laminated plates by using 3D elasticity theory by Pagano[17] and Srinivas and Rao [115] have been very useful to compare the accuracy of $2 \mathrm{D}$ displacement theories [12, 62, 116-118], they are limited to the case where material properties are piece-wise constant and hence not useful for FGMs which have smoothly and continuously varying properties such as moduli, Poisson's 
Table 4. Some of the research works in the area of functionally graded plates.

\begin{tabular}{|c|c|c|}
\hline Research & Area of analysis & Solution approach \\
\hline $\begin{array}{l}\text { Duc, Cong } \\
\text { and } \\
\text { Quang } \\
\text { [104] }\end{array}$ & $\begin{array}{c}\text { Nonlinear dynamic analysis of piezoelectric FGM plates } \\
\text { resting on Pasternak type elastic foundations and } \\
\text { subjected to mechanical and thermal loads. For the first } \\
\text { time simultaneous impact of material properties, elastic } \\
\text { support, stiffeners under thermal stress and loads on the } \\
\text { vibration response is studied. Impact of temperature on } \\
\text { piezoelectric layer, stiffeners and plate overall is } \\
\text { analyzed }\end{array}$ & $\begin{array}{c}\text { Based on FSDT considering geometrical nonlinearity using } \\
\text { von Karman theory, initial geometrical imperfections } \\
\text { and different types of boundary conditions }\end{array}$ \\
\hline $\begin{array}{l}\text { Zhang and } \\
\text { Zhou } \\
\text { [105] }\end{array}$ & $\begin{array}{c}\text { Mechanical and post-buckling analysis of rectangular FG } \\
\text { plates on nonlinear elastic foundation. Post buckling } \\
\text { analysis of plates with } 2 \text { opposite edges as simply } \\
\text { supported and other } 2 \text { clamped edges is novel. Effect of } \\
\text { volume fraction, boundary stiffness and thermal } \\
\text { conditions is analyzed }\end{array}$ & $\begin{array}{c}\text { Based on concept of physical neutral surface and HSDT. } \\
\text { Approximate solutions of FGM rectangular plates are } \\
\text { found using multi-term Ritz method }\end{array}$ \\
\hline $\begin{array}{l}\text { Bateni et al } \\
\quad[106]\end{array}$ & $\begin{array}{l}\text { Instability analysis of thick through-the-thickness FGM } \\
\text { plates under mechanical and thermal loads is analyzed. } \\
\text { Uniform shear, Uni-axial or biaxial loads, uniform } \\
\text { temperature rise, heat conduction across the thickness, } \\
\text { and combined cases are analyzed for clamped only } \\
\text { boundary conditions }\end{array}$ & $\begin{array}{l}\text { A } 4 \text { variable refined plate theory with parabolic distribution } \\
\text { of shear strains through-the-thickness is used. A multi- } \\
\text { term Galerkin formulation is used for critical buckling } \\
\text { load/temperature evaluation }\end{array}$ \\
\hline $\begin{array}{l}\text { Abrate } \\
\qquad[107,108]\end{array}$ & $\begin{array}{l}\text { Free vibrations, buckling, and static deflections of isotropic } \\
\text { and orthotropic FGM plates. }\end{array}$ & $\begin{array}{l}\text { Using the proper selection of the reference surface the } \\
\text { coupling between the in-plane and bending deformations } \\
\text { is eliminated and it is shown that the natural frequencies } \\
\text { and buckling loads can be obtained from homogeneous } \\
\text { plates with scaling factor considering not only CLPT bu } \\
\text { also FSDT and higher order theories. }\end{array}$ \\
\hline $\begin{array}{l}\text { Ferreira et al } \\
\quad[109,110]\end{array}$ & $\begin{array}{l}\text { Static deformations of a simply supported functionally } \\
\text { graded plate }\end{array}$ & $\begin{array}{c}\text { Based on the meshless collocation method, the } \\
\text { multiquadric radial basis functions and a } 3^{\text {rd }} \text { order theory } \\
\text { is used to analyze static deformations of FG square plates } \\
\text { of different aspect ratios }\end{array}$ \\
\hline $\begin{array}{l}\text { Vel and } \\
\text { Batra } \\
\text { [111] } \\
\text { Brischetto }\end{array}$ & $\begin{array}{c}\text { Free and forced vibrations of simply supported metal- } \\
\text { ceramic rectangular FG plates having a power law } \\
\text { variation of volume fractions of the constituents through } \\
\text { the thickness }\end{array}$ & $\begin{array}{l}\text { Extension of earlier 3D exact solution by considering } \\
\text { displacement function that identically satisfy simply } \\
\text { supported boundary conditions and reduce the PDEs to } \\
\text { set of coupled ordinary differential equations }\end{array}$ \\
\hline $\begin{array}{l}{[112]} \\
\text { Tran et al }\end{array}$ & $\begin{array}{l}\text { Static analysis of single and multilayered simply supported } \\
\text { plates and shells under harmonic loads }\end{array}$ & $\begin{array}{l}\text { Exact 3D solution with 3D equilibrium equations under } \\
\text { general orthogonal curvilinear coordinates }\end{array}$ \\
\hline [113] & $\begin{array}{l}\text { Nonlinear bending and post-buckling analysis of FGM } \\
\text { plate in thermal environment. }\end{array}$ & $\begin{array}{l}\text { Equilibrium and stability equations of plate are solved } \\
\text { using isogeometric analysis (IGA) in combination with } \\
\text { higher-order shear deformation theory (HSDT) with von } \\
\text { Karman assumption for geometric non linearity }\end{array}$ \\
\hline
\end{tabular}

ratio and density in preferred directions. Some of the major conclusions drawn by the authors are as under.

(i) Most of the 2D theories for FG plates consider only the transverse shear deformation effect and very few theories consider the effect of both transverse shear and transverse normal deformations.

(ii) Most of the 2D theories validate the global responses of FG plates by comparing the results with 3D elasticity solutions only. In very few studies, the comparison of the accuracy with analytically predicted global responses of FG plates using various higher order theories.

(iii) Most of the FG plate research is purely analytical or with numerical simulation.
The authors recommend use of the improved 2D theories in place of 3D models in the interest of computational cost and efficiency.

Zhang et al [119] developed a novel size dependent plate model for bending, free vibration and buckling analysis of FG microplates on elastic foundation. They leveraged the new refined shear deformation theory by Thai and Choi [38, 120] for FG plates on elastic foundations (theory having only four unknowns and not requiring sheer correction factor) and strain gradient elasticity theory by Lam et al [121] to develop their model with only four displacement variables and also introduced three material length scale parameters (associated with dilatation gradient tensor, deviatoric stretch gradient tensor and symmetry part of rotation gradient tensor, respectively) 
Belabed et al [122] developed a shear and normal deformation theory for FGM plates which reduces the number of unknowns to five and simplifies the governing equations. The approach accounts for both shear deformation and thickness stretching effects by a hyperbolic variation of all displacements across the thickness and meets stress free BC criteria on the top, bottom surfaces without shear deformation factor. The comparison of the analytical solutions of simply supported plates for bending and free vibration cases with 3D and quasi-3D approaches show that not only the theory is accurate but also simple in predicting the bending and free vibration responses. The results match closely with 3D solution even for thick plates $(\mathrm{a} / \mathrm{h}=$ Mantari and Soares [123] developed a new trigonometric higher-order theory in which the stretching effect is included). The authors extended the trigonometric shear deformation theory for isotropic and composite laminated and sandwich plates by Mantari et al [13] to FG plates including the stretching of thickness. The material properties vary exponentially through the thickness. Their paper analyzes exponentially graded plates subjected to transverse bi-sinusoidal load for simply supported boundary conditions. They compared the results with (a) 3D exact solutions [124]. (b) Trigonometric plate theory (TPT) which includes Levy's sinus function validated by Stein [125] and used by Touratier [19] and recently adapted to FGM and exponentially graded material (EGM) by Zenkour [126, 127], (c) an HSDT result by Zenkour [127] and (d) HSDT developed by Mantari et al [25] and Mantari and Soares [128] without the stretching effect. Also they concluded that stretching effect allows getting improved transverse displacement and transverse normal stresses results. The results for deflection for thick plates slightly under-predict the 3D solution while results in Mantari and Soares [128] over-predict which according to authors highlights the need for including the transverse expansion of plate's thickness for accuracy and tendency.

Mantari and Soares [129] recently extended on earlier work Mantari and Soares [123] and developed a 4-unknown quasi-3D shear deformation theory with stretching effect for the static analysis of advanced composite plates. The effective material properties of the functionally and exponentially graded plates (FGPs and EGPs), denoted as $\mathrm{P}(\mathrm{z})$ vary through the plate thickness $\mathrm{h}$ according to the function $\mathrm{V}(\mathrm{z})$ as below.

For exponentially graded plates

$$
P(z)=V_{(z)} P_{b} V_{(z)}=e^{p\left(\frac{z}{h}+\frac{1}{2}\right)}
$$

For powerly graded plates

$$
P(z)=\left(P_{t}-P_{b}\right) V_{(z)}+P_{b}, V_{(z)}=\left(\frac{z}{h}+\frac{1}{2}\right)^{p}
$$

where $\mathrm{P}_{\mathrm{t}}$ and $\mathrm{P}_{\mathrm{b}}$ denote the property of the top and bottom faces of the panel, respectively, and $p$ is the exponent that specifies the material variation profile through the thickness. The shape functions used in displacement field are

$$
\mathrm{f}(\mathrm{z})=\left(\frac{\mathrm{h}}{\mathrm{m}}\right) \tanh \left(\frac{\mathrm{mz}}{\mathrm{h}}\right)+\mathrm{z}^{3}, \quad \mathrm{~g}(\mathrm{z})=\operatorname{nf}(\mathrm{z})
$$

The authors have considered the moduli $\mathrm{E}$ and $\mathrm{G}$ varying as per these equations. One of the main points of this research is the proper selection of the shear strain shape functions for the result accuracy. The authors have used iterative methodology to arrive at the values of parameters $m$ and $n$ used in the shear strain function by calculating the stresses, strains which provide minimum error threshold with 3D solution by Carrera et al [124] and quasi-exact solution by Zenkour [127] at a specific location on plate. The displacements and stresses with the selected $m$ and $n$ are validated with $3 \mathrm{D}$ solution throughout the plate thickness [124]. Thus the values of $\mathrm{m}$ and $\mathrm{n}$ were optimized at 0.4 and $2 / 15$, respectively. The authors performed static analysis for various PGPs and EGPs with different geometry and material properties. The exponential variation of properties was considered as per Carrera [124] and the powerly variation was considered as per Mantari and Soares [123] and accurately solved by Carrera [124]. The EGP results were compared with the 3D exact solutions and a HSDT with stretching effect by Zenkour [126] and a recently developed quasi-3D HSDT with 6 unknowns Mantari and Soares [123]. The authors state that results improved on Mantari and Soares [123] when compared with 3D solution. The authors conclude that their theory with 4 unknowns is capable to produce very accurate results compared with the CLPT, FSDT and other HSDTs with higher number of unknowns and thus offers potential for further research. Further, Mantari [130] has used the 4-unknown approach to analyze the free vibrations of FGPs including stretching effect and shows close agreement to $3 \mathrm{D}$ results.

Thus the FGMs with their superior properties over conventional materials are leading researchers to explore various solution approaches to address complex real life phenomena such as delaminations, transverse and inplane displacement coupling and effect of foundation stiffness, material grading index on mechanical response of thick plates subjected to mechanical and/or thermal loads, etc.

\section{Meshless approximations}

While numerical techniques like FEM and FDM are extensively used for the analysis of composite structure, researchers have developed additional techniques to address some of the shortcomings of these methods. The meshless methods are developed which address issues such 
as mesh distortions, need for very high computing power, re-meshing, etc.

The earliest meshless method was smooth particle hydrodynamics (SPH) proposed by Gingold and Monaghan [131]. This was followed by diffuse element method (DEM) by Nayroles et al [132] based on Moving Least Square approximation (MLS) proposed by Lancaster and Salkauskas [133]. Later Belytschko et al [134] proposed element free Galerkin method and applied for thin plates [135, 136] and shells [137]. Liu et al [138] developed a reproducing kernel particle method (RKPM) using a correction function in SPH. Liu et al [139] and Li and Liu [140] also developed a moving least-square reproducing kernel methods (MLSRK) using moving least-square interpolation function. RKPM has been used in research by Donning and Liu [141] for beam and plate analysis and by Li et al [142] for thin shells. A systematic description of various meshless methods, their usage and applications along with problems associated with element free methods is explained by Liu [143]. Atluri [144] developed a meshless local Galerkin (MLPG) method based on local symmetric weak form (LSWF) for linear potential problems and numerically solved various problems such as cantilever beam, infinite plate with hole, etc. [145] and thin plates [146]. The author found that the MLPG provides more accuracy than FEM, does not require a smoothing technique to compute the stresses and strains and has an excellent rate of convergence for displacements as well as for the strain energy. For plate problems, very good accuracy is achieved for $\mathrm{C} 1$ and even $\mathrm{C} 2$ approximations. Some of the recent research work in various areas of structural analysis are presented here. Recently, Thai et al [147] presented a rotation-free moving Kriging interpolationbased (MKI) meshfree formulation based on 2 variable refined plate theory for static, free and buckling analysis of isotropic plates. Their method provides stability of the MKI shape functions using quartic spline based correlation functions with just 2 DOFs per node.

\subsection{Static structural and thermal analysis}

Vaghefi et al [148] proposed a meshless local PetrovGalerkin (MLPG) method for 3D thermo-elastoplastic analysis of thick functionally graded (FG) plates subjected to combined thermal and mechanical loads. The weak form was developed using 3D equilibrium equations and then transformed into local integral equations. Using brickshaped local sub-domains help to have easy and accurate approximation of the solution variables using weak form of integration. Precise solution could be obtained by introducing more nodes in the direction of material variation. Wu et al [149] have developed a meshless collocation (MC) and an element-free Galerkin (EFG) method, using the differential reproducing kernel (DRK) interpolation for the quasi-three-dimensional (3D) analysis of simply supported, multilayered composite and functionally graded material (FGM) plates. The weak and strong formulations of this analysis and corresponding governing equations are derived using Reissner mixed variational theorem (RMVT). The authors have studied some critical points of these two methods such as the optimal support size, the highest order of basis functions and the total number of nodes. The results for the simply-supported multi-layered composite plates, FG plates show the rapid convergence of both MC and EFG approaches to the available exact 3D solution where the highest order of basis functions (n) is suggested to be 3 , the number of uniformly distributed nodes $\mathrm{Np}$ to be 11 and the radius of the influence zone a to be 3.1 times the spacing between the adjacent nodes. It is also found by them that the deviation of the variables increases with the increase of the material property gradient index.

Recently Singh et al [150] developed a procedure for bending analysis of laminated composite and sandwich plates using different radial basis functions and higherorder shear deformation theory. Their technique is insensitive to spatial dimension and considers only a cloud of nodes (centers) for the spatial discretization of both the problem domain and the boundary. The results for simply supported isotropic, symmetric cross-ply composite and sandwich plate show that the convergence of the polynomial function is faster as compared to other radial basis functions, whereas Gaussian function takes the least solution time.

Sator et al [151] investigated static response of thin and/ or thick elastic functionally graded (FG) plates with focus on effect of material coefficient gradation which bring in coupling effect between plate deflection and in-plane deformation and variable bending stiffness. The analysis covers Kirchhoff-Love theory (KLT) as well as the 1st and 3rd order shear deformation plate theory (SDPT). The authors have proposed a strong formulation combined with Moving Least Square (MLS) approximation for field variables as an alternative to having higher order derivatives in governing equations which affect the accuracy and computational time. The meshless formulation based on MLS addresses the higher order problem by decomposition formulation. The authors point out that for FGM plate having transverse gradation of Young's modulus, the plane stress formulation is questionable. Jalušić et al [152] presented a mixed meshless local Petrov-Galerkin (MLPG) collocation method for analyzing 2D heterogeneous structures. The heterogeneity was represented by creating material sub-domains having different linear elastic properties. Moving least square approximation was used and it was found that by putting displacement continuity and traction reciprocity conditions at the nodes representing the interface boundary, results were found very close to available analytical, numerical as well as standard displacement meshless method. Thus the authors demonstrated a more robust and stable material discontinuity modeling. 
Kaewumpai and Luadsong [153] presented an alternative approach of meshless method based on two-field variable local weak form for thin simply supported plates under various types of loads (hydrostatic, sinusoidal and uniformly distributed). The moving kriging interpolation method was used to define nodal shape functions as well as Heaviside step function for the two-field scheme. This was shown to simplify the local weak form of the bi-harmonic equation and also in applying simple boundary conditions and yet provide accurate results compared to exact method based on maximum relative and root mean square relative error.

Belinha et al [154] developed a method which combined the connectivity simplicity of low order finite element method and flexibility of meshless method. This method based on the Natural Radial Element Method (NREM) was extended to thick plates. This method makes the integration mesh automatically defined by the unstructured nodal mesh over the problem domain using a natural neighbor geometrical concept. This method helped to make displacement and resultant stress field smooth and accurate, showed good behavior with random irregular nodal meshes and also showed fast convergence to analytical solution.

\subsection{Free vibrations and buckling analysis}

Zhu and Liew [155] carried out free vibration analyses of metal and ceramic FG plates with the local Kriging meshless method. The eigenvalue equations of free vibration were based on FSDT and the local Petrov-Galerkin formulation. Numerical convergence was studied on square, skew and quadrilateral plates. Zhu and Liew [156] introduced thermal effects to analyze free vibrations using local Kriging meshless method. Cui et al [157] proposed a smoothed Hermite radial point interpolation method (Hermite-RPIM) using gradient smoothing operation for thin plates. The authors have used a smoothed Galerkin weak form to discretize the governing partial differential equations, and a curvature smoothed operation is developed to relax the continuity requirement and achieve accurate bending solutions. Zhao et al [158] proposed an elementfree $\mathrm{kp}$-Ritz method to analyze free vibration of metalceramic FG plates whose material properties vary continuously throughout thickness by a power law of the volume fractions of plate constituents. The authors used FSDT to account for transverse shear strain and rotary inertia and a mesh-free kernel particle functions to approximate the twodimensional displacements. The impact of volume fraction, boundary conditions and the length-to-thickness ratio on the fundamental frequency characteristics of plates was studied. The results show that the volume fraction exponent that ranges from 0 to 5 has significant but effect of lengthto-thickness ratio on frequency is independent of volume fraction. The shear correction factor did not influence frequency for plates with $\mathrm{a} / \mathrm{h} \geq 10$. Zhang et al [159] have studied mechanical and thermal buckling of metal-ceramic FG plates using a local Kriging meshless method. The method is developed based on local Petrov-Galerkin weakform formulation combined with shape functions having the Kronecker delta function property, constructed by the Kriging interpolation. Fantuzzi et al [160] have analyzed free vibrations of arbitrary shaped laminated composite plates using radial basis function based on differential quadrature (RBF-DQ) to overcome issues of using only radial basis functions for plate problems. They found good agreement with existing techniques based on differential quadrature and also that their method in some cases allows for less using less grid points than DQ method typically when subdomains of great dimensions are used. They could also achieve a uniform grid distribution for most of the problems analyzed using RBF-DQ method. Bui et al [161] developed a new meshless formulation based on moving Kriging interpolation method (MK) and applied it for high frequency modes analysis of square and circular ReissnerMindlin plates. They incorporated a technique where approximation functions for the rotational degrees of freedom (DOF) are used as the derivatives of the approximation function for the translational DOF to eliminate shear locking effect which is seen when using thick plate theories to analyze for thin plates. In a novel approach used first time, Dey et al [162] developed a polynomial neural network (PNN) model to analyze variation of layer-wise random input variables (such as ply orientation, ply-thickness and material properties) to predict the stochastic natural frequencies of composite laminates plates under random vibrations. Also the effect of noise on the frequency is analyzed by combining FEM formulation with PNN and they found that the approach is computationally economical with good accuracy as compared to conventional Monte Carlo simulations with many FEM simulations. Mallela and Upadhyay [163] leveraged the artificial neural network (ANN) analysis model for predicting the buckling load of laminated composite stiffened panels subjected to in-plane shear loading. Their approach can be useful for optimization studies for design of weight sensitive structures. Extending the combined FE and stochastic model techniques further, Vosoughi et al [164] developed a model by mixing FEM, genetic algorithm (GA) and particle swarm optimization (PSO) techniques to maximize buckling loads on laminated composite plate by finding optimum fibers orientation. FEM was used to solve higher order shear deformation plate equations while PSO was used to improve the performance of the generic solution algorithm.

\subsection{Fracture analysis and delamination effects}

Meshless methods are used since many years typically for crack growth studies. [165, 166]. Later Lee and Yoon [166] proposed an enhanced element-free Galerkin (EFG) method with enhancement functions to improve the solution 
accuracy for linear elastic fracture problem. Li and Liu [167] carried out a detail review of meshfree/particle methods and their applications. They noted that the future challenges that need to be addressed involve having costeffective meshfree-Galerkin method, scalable implementation of essential boundary conditions, accurate nodal integration strategies and stabilization schemes for both discretized weak form as well as collocated strong form formulations. Zhuang et al [168] developed a numerical framework is developed for 3D fracture modeling where a meshless method, the element-free Galerkin method, is used for stress analysis and level sets are used accurately to describe and capture crack evolution. The authors extended their 2D tying procedure to 3D for accurate crack front closure. Recently, Khazal et al [169] deployed an extended element free Galerkin method (XEFGM) for fracture analysis of FGM. The authors have used orthotropic enrichments functions along with the sub-triangle technique for enhancing the Gauss quadrature accuracy near the crack, and the incompatible interaction integral method is employed to calculate the stress intensity factors. The numerical results showed that this approach provides more accurate results with less number of nodes (DOFs) in comparison with the unenriched EFGM and other conventional methods for several FGM problems with different crack locations and loadings.

Zhang et al [170] performed and elastostatic crack analysis in 3D, continuously non-homogeneous, isotropic and linear elastic FGMs by advanced BEM method as an extension to earlier work on 2D crack analysis such as Zhang et al [171] and 3D static analysis by Gao et al [172]. The simplicity of their method is that the meshless scheme developed which requires only the conventional boundary discretization and additional interior nodes instead of interior cells or meshes. They analyzed the effects of the material gradation on the crack-opening-displacements and the stress intensity factors. The results show that material gradation in $\mathrm{y}$ - or in $\mathrm{z}$ - direction reduces mode-I SIF. For y-direction gradation the mode-II and III SIFs are not zero as in case of homogeneous material.

Zhuang et al [173] proposed a new meshless sub-region radial point interpolation method (MS-RPIM) for linear elastic fracture mechanics. The Williams expansions of stress field for mode I/II crack is used as the trial functions in crack tip region, the meshless radial point interpolation is used for the rest of domain, and a mixed variational principle is used for discretization. The advantages of MSRPIM is that it requires only very few nodes around the crack tip to obtain smooth stress and accurate results and the stress intensity factors can be directly obtained as part of the solution and no additional effort via post-processing. Aslan and Sahin [174] studied the effects of the delamination size on the critical buckling load and compressive failure load of E-glass/epoxy composite laminates with multiple large delaminations. They carried out a numerical and experimental study to determine the buckling load of rectangular composite plates made of $\left(0^{\circ} / 90^{\circ} / 0^{\circ} / 90^{\circ}\right)$ with and without delaminations. They found that the longest and near-surface delamination size influences the buckling load and compressive failure load of composite laminates. However, the size of beneath delaminations has no significant effect on the buckling load and compressive failure load of composite laminates. The meshless methods offer great advantages over conventional numerical methods especially for discontinuities and large deformation problems as pointed by Liew et al [175]. Researchers such as Macri and De [176], Ching and Hoe [177] have identified multi-scale modelling of composite materials and structures as an attractive option for large deformations and cases where macroscopic material properties are different than material level. Shojaei et al [178] developed a new coupled meshless method for 2D transient elastodynamic problems and for crack propagation problems. The novelty of their method is the coupling between finite point method (FPM) and a discretized form of Peridynamics which uses much smaller number of nodes for Peridynamic-only model and is also free from the presence of ghost forces.

\section{Conclusions}

A review of the evolution of plate theories for composites along with the details of recent research work in the structural analysis based on available literature is presented in the present article. An effort has been made to include the important contribution in a range of composite plate problems with focus on recent work and emerging trends. The general remarks from the research survey are as follows:

(1) It is seen that as the usage of the composite material is increasing in the critical applications like renewable energy, transportation and biomedical fields, the direction of research is driven by the criteria such as (a) accuracy with 3D elastic solution while maintaining low cost of computation, (b) consideration of realistic boundary conditions, delamination effects and consideration of material property discontinuity at the layer interfaces, (c) simplicity of analytical techniques such as meshfree approximations and (d) lowering computational cost of analysis while considering random system parameters.

(2) The research evolved from classical, first order and other approximation of equivalent single layer theories to higher order theories covering polynomial, trigonometric, exponential and hyperbolic shape functions so as to accurately represent transverse shear strain effects and meet stress-free surface conditions and yet avoiding use of any shear correction factors. The development of higher order shear deformation theories helped to develop more accurate plate models than classical and FSDT by considering cross-section warping and 
discontinuities in thick plates. They are also effective in sandwich plates and non-uniform layups.

(3) The Layer-wise and zig-zag models have emerged to address the shortcomings of the ESL theories to address the displacement and transverse shear stress continuity across layer interfaces and have been especially useful for sandwich plates and are effective in predicting the localized behavior such as near notches, holes or discontinuities. They can predict the interlaminar stresses better than ESL theories. The zig-zag theories cannot predict the transverse shear stresses directly from constitutive equations and need 3D equilibrium equations. However, the number of unknowns in governing equations depend on the number of layers and can take large computational resources. Some recent work is being done to help maintain interlaminar continuity and yet reduce the number of independent variables which helps in reducing computation time. It is seen that the approach of combining axiomatic/ asymptotic model with Carrera's Unified Formulation (CUF) to develop refined models with reduced terms in equation is increasing the suitability of layer-wise models to complex practical problems with high degrees of freedom.

(4) Newer approaches such as displacement potential based 2D theories provide answer to scenarios where pure stress based boundary conditions could not address mixed boundary condition problems. They are also computationally more efficient than ESL theories.

(5) More and more research is getting focused towards Functionally Graded Materials due to their advantages such as lesser probability of debonding at high thermal loading and less residual stresses as their microstructure changes continuously unlike carbon reinforced composites. Also it is seen that most of the $2 \mathrm{D}$ theories for FG plates do not consider both transverse shear and transverse normal strain effects. The 3D solutions for FGM plates considering power law variation of constituent properties are not available and also there is a need to assess the accuracy and computational cost of applying higher order theories to FGM plate problems with complex geometry and boundary conditions.

(6) The usage of meshless methods is increasing due to advantages over conventional methods especially for complex geometries, large deformations and geometry discontinuities. Multiscale modeling of composites using meshless methods such as MLPG is increasing however there is a need to develop efficient algorithms and stabilization techniques to reduce the computational costs and yet have high accuracy. The plate analysis research based on pure meshless methods such as Natural Radial Element Method (NREM) for FG plates is showing great promise on account of accuracy, simplicity and low computation costs.
(7) Novel methods such as hierarchical and region-byregion modeling have evolved which address the issue of economics of computation while maintaining solution accuracy especially in cases of non-uniform domains, cut-outs, discontinuities and material/ boundary condition changes at interfaces.

(8) Researchers are increasingly using the mixed mode solution formulations for plate problems. Their aim is to address (a) the complexities and uncertainties of the random input parameter variations, (b) needs of design optimization runs while maintaining computational economy and (c) to simplify and improve performance of the solution models for generic plate shapes and high order dynamic vibration studies. These approaches include combined numerical FE and stochastic techniques (e.g. artificial neural network and particle swarm optimization), XFEM methods as well as Rayleigh-Ritz model combined with wavelet multi-elements algorithm.

\section{References}

[1] Global Wind Energy Report 2016 (http: //gwec.net/publications/global-wind-report-2/global-wind-report-2016/)

[2] Diodati G, Concilio A, Ricci S, Gaspari A, Huvelin F, Dumont A and Godadrd J L 2013 Estimated performance of an adaptive trailing-edge device aimed at reducing fuel consumption on a medium-size aircraft. In: Proc. SPIE 8690, Industrial and Commercial Applications of Smart Structures Technologies, San Diego, California, USA, March

[3] Whitney J M and Leissa A W 1970 Analysis of simply supported laminated anisotropic plates. AIAA J. 8: 28-33

[4] Ashton J E 1970 Anisotropic plate analysis-boundary conditions. J. Compos. Mater. 4: 162-171

[5] Reissner E 1972 A consistent treatment of transverse shear deformations in laminated anisotropic plates. AIAA J. 10: 716-718

[6] Mindlin R D 1951 Influence of Rotary Inertia and Shear on Flexural Motions of Isotropic, Elastic Plates. ASME $J$. Appl. Mech. 18: 31-38

[7] Whitney J M and Pagano N J 1970 Shear deformation in heterogeneous anisotropic plates. J. Appl. Mech. 37: 1031-1036

[8] Reddy J N, Khdeir A A and Librescu L 1987 Lévy type solutions for symmetrically laminated rectangular plates using first-order shear deformation theory. J. Appl. Mech. 54: 740-742

[9] Reddy J N 1984 A simple higher-order theory for laminated composite plates. J. Appl. Mech. 51: 745-752

[10] Kant T and Manjunatha B S 1994 On accurate estimation of transverse stresses in multilayer laminates. Comput. Struct. 50: 351-365

[11] Khdeir A A and Librescu L 1988 Analysis of symmetric cross-ply laminated elastic plates using a higher-order 
theory: Part I-Stress and displacement. Compos. Struct. 9: 189-213

[12] Kant T and Swaminathan K 2001 Free vibration of isotropic, orthotropic, and multilayer plates based on higher order refined theories. J. Sound Vib. 241: 319-327

[13] Mantari J L, Oktem A S and Soares C G 2012 A new trigonometric shear deformation theory for isotropic, laminated composite and sandwich plates. Int. J. Solids Struct. 49: $43-53$

[14] Carrera E, Matteo F and Enrico Z 2013 Laminated beam analysis by polynomial, trigonometric, exponential and zigzag theories. Eur. J. Mech. A-Solid 41: 58-69

[15] Sayyad A S and Ghugal Y M 2012 Bending and free vibration analysis of thick isotropic plates by using exponential shear deformation theory. Appl. Comput. Mech. 6

[16] Sayyad A S and Ghugal Y M 2014 Buckling and free vibration analysis of orthotropic plates by using exponential shear deformation theory. Lat. Am. J. Solids Struct. 11: $1298-1314$

[17] Pagano N J 1970 Exact solutions for rectangular bidirectional composites and sandwich plates. J. Compos. Mater. 4: $20-34$

[18] Reddy J N 1984 Exact solutions of moderately thick laminated shells. J. Eng. Mech. 110: 794-809

[19] Touratier M 1991 An efficient standard plate theory. Int. J. Eng. Sci. 29: 901-916

[20] Soldatos K P 1992 A transverse shear deformation theory for homogeneous monoclinic plates. Acta Mech. 94: $195-220$

[21] Lu X and Liu D 1992 An interlaminar shear stress continuity theory for both thin and thick composite laminates. $J$. Appl. Mech. 59: 502-509

[22] Lee C Y and Liu D 1992 An interlaminar stress continuity theory for laminated composite analysis. Comput. Struct. 42: $69-78$

[23] Becker W 1993 Closed-form solution for the free-edge effect in cross-ply laminates. Compos. Struct. 26: 39-45

[24] Becker W, Pei P J and Petra N 1999 Interlaminar stresses at the free corners of a laminate. Compos. Struct. 45: 155-162

[25] Mantari J L, Oktem A S and Soares C G 2012 A new higher order shear deformation theory for sandwich and composite laminated plates. Compos. Part B-Eng. 43: 1489-1499

[26] Aydogdu M 2009 A new shear deformation theory for laminated composite plates. Compos. Struct. 89: 94-101

[27] Reddy J N and Liu C F 1985 A higher-order shear deformation theory of laminated elastic shells. Int. J. Eng. Sci. 23: $319-330$

[28] Schwab C, 1996. A-posteriori modeling error estimation for hierarchic plate models. Numer. Math. 74: 221-259

[29] Ambartsumian S A 1958 On theory of bending plates. Isz. Otd. Tech. Nauk. AN SSSR 5, 69-77

[30] Mantari J L, Oktem A S and Soares C G 2011 Static and dynamic analysis of laminated composite and sandwich plates and shells by using a new higher-order shear deformation theory. Compos. Struct. 94: 37-49

[31] Srinivas S 1973 A refined analysis of composite laminates. J. Sound Vib. 30: 495-507

[32] Song X, Wang K M, Ai Y T, Sha Y D and Shi H 2009 Analysis of isotropic, sandwich and laminated plates by a meshless method and various shear deformation theories. Compos. Struct. 91: 31-37
[33] Ferreira A J M, Batra R C, Roque C M C, Qian L F and Martins P A L S 2005, "Static analysis of functionally graded plates using third-order shear deformation theory and a meshless method. Compos. Struct. 69: 449-457

[34] Karama M, Afaq K S and Mistou S 2003 Mechanical behavior of laminated composite beam by the new multilayered laminated composite structures model with transverse shear stress continuity. Int. J. Solids Struct. 40: 1525-1546

[35] Shimpi R P 2002 Refined plate theory and its variants. AIAA J. 40: 137-146

[36] Shimpi R P and H G Patel 2006 A two variable refined plate theory for orthotropic plate analysis. Int. J. Solids Struct. 43: 6783-6799

[37] Alipour M M. 2016 An analytical approach for bending and stress analysis of cross/angle-ply laminated composite plates under arbitrary non-uniform loads and elastic foundations. Arch. Civ. Mech. Eng. 16(2): 193-210

[38] Thai HT, Choi DH. 2013 Analytical solutions of refined plate theory for bending, buckling and vibration analyses of thick plates. Appl. Math. Model. 37(18): 8310-8323

[39] Thai H T and Kim S E 2011 Levy-type solution for buckling analysis of orthotropic plates based on two variable refined plate theory. Compos. Struct. 93(7): 1738-1746

[4] Thai H T, Kim S E 2012 Levy-type solution for free vibration analysis of orthotropic plates based on two variable refined plate theory. Appl. Math. Model. 36(8): 3870-3882

[41] Wanji C and Zhen W 2008 A selective review on recent development of displacement-based laminated plate theories. Recent Patents on Mechanical Engineering 1: 29-44

[42] Whitney J M 1969 The effect of transverse shear deformation on the bending of laminated plates. J. Compos. Mater. 3: 534-547

[43] Whitney J M 1973 Shear correction factors for orthotropic laminates under static load. J. Appl. Mech. 40: 302-304

[44] Murakami H 1986 Laminated composite plate theory with improved in-plane responses. J. Appl. Mech. 53: 661-666

[45] Sciuva M D 1986 Bending, vibration and buckling of simply supported thick multilayered orthotropic plates: an evaluation of a new displacement model. J. Sound Vib. 105: 425-442

[46] Carrera E and Demasi L 2002 Classical and advanced multilayered plate elements based upon PVD and RMVT. Part 2: Numerical implementations. Int. J. Numer. Methods Eng. 55: 253-291

[47] Carrera E and Demasi L 2002 Classical and advanced multilayered plate elements based upon PVD and RMVT. Part 1: Derivation of finite element matrices. Int. J. Numer. Methods Eng. 55: 191-231

[48] Carrera E 2004 On the use of the Murakami's zig-zag function in the modeling of layered plates and shells. Comput. Struct. 82: 541-554

[49] Li X and Liu D 1995 A laminate theory based on globallocal superposition. Commun. Numer. Methods Eng. 11: 633-641

[50] Sciuva M D 1995 A third-order triangular multilayered plate finite element with continuous interlaminar stresses. Int. J. Numer. Methods Eng. 38: 1-26

[51] Cho M and Oh J 2004 Higher order zig-zag theory for fully coupled thermo- electric-mechanical smart composite plates. Int. J Solids Struct. 41: 1331-1356 
[52] Sciuva M D and Marco G 2003 A global/local third-order Hermitian displacement field with damaged interfaces and transverse extensibility: analytical formulation. Compos. Struct. 59: 419-431

[53] Kapuria S, Dumir P C and Jain N K 2004 Assessment of zigzag theory for static loading, buckling, free and forced response of composite and sandwich beams. Compos. Struct. 64: 317-327

[54] Wu Z, Chen R and Chen W 2005 Refined laminated composite plate element based on global-local higherorder shear deformation theory. Compos. Struct. 70: $135-152$

[55] Wu Z and Chen W 2006 An efficient higher-order theory and finite element for laminated plates subjected to thermal loading. Compos. Struct. 73: 99-109

[56] Rao M K and Desai Y M 2004 Analytical solutions for vibrations of laminated and sandwich plates using mixed theory. Compos. Struct. 63: 61-373

[57] Neves A M A, Ferreira A J M, Carrera E, Cinefra M, Roque C M C, Jorge R M N and Soares C M M 2013 Static, free vibration and buckling analysis of isotropic and sandwich functionally graded plates using a quasi-3D higher-order shear deformation theory and a meshless technique. Compos. Part B-Eng. 44: 657-674

[58] Li XY and Liu D 1997 Generalized laminate theories based on double superposition hypothesis. Int. J. Numer. Methods Eng. 40: 1197-1212

[59] Pagano N J 1969 Exact solutions for composite laminates in cylindrical bending. J. Compos. Mater. 3: 398-411

[60] Wu Z and Chen W J 2007 A study of global-local higherorder theories for laminated composite plates. Compos. Struct. 79: 44-54

[61] Matsunaga H 2002 Assessment of a global higher-order deformation theory for laminated composite and sandwich plates. Compos. Struct. 56: 279-291

[62] Kant T and Swaminathan, K 2002 Analytical solutions for the static analysis of laminated composite and sandwich plates based on a higher order refined theory. Compos. Struct. 56(4), 329-344

[63] Szabo B A and Sahrmann G J, 1988. Hierarchic plate and shell models based on p-extension. Int. J. Numer. Methods Eng. 26: 1855-1881

[64] Babuska I, Szabo B A and Actis R L 1992 Hierarchic models for laminated composites. Int. J. Numer. Methods Eng. 33: 503-535

[65] Actis R L, Szabo B A and Schwab C 1999 Hierarchic models for laminated plates and shells. Comput. Methods Appl. Mech. Eng. 172: 79-107

[66] Ahmed NU, Basu PK 1994 Higher-order finite element modelling of laminated composite plates. Int. J. Numer. Methods Eng. 37: 123-139

[67] Reddy J N 1987 A generalization of two-dimensional theories of laminated composite plates. Commun. Appl. Numer. Methods 3: 173-180

[68] Mitchell J A and Reddy J N 1995 A refined hybrid plate theory for composite laminates with piezoelectric laminae. Int. J. Solids Struct. 32: 2345-2367

[69] Zuo H, Yang Z, Chen X, Xie Y and Miao H 2015 Analysis of laminated composite plates using wavelet finite element method and higher-order plate theory. Compos. Struct. 131: 248-258
[70] Fantuzzi N, Tornabene F, Viola E and Ferreira A J 2014 A strong formulation finite element method (SFEM) based on RBF and GDQ techniques for the static and dynamic analyses of laminated plates of arbitrary shape. Meccanica 49(10): 2503-2542

[71] Viola E, Tornabene F, Ferretti E, Fantuzzi N. 2013 On static analysis of composite plane state structures via GDQFEM and cell method. CMES 94(5): 421-458

[72] Angioni S L, Visrolia A and Meo M 2012 Combining $\mathrm{X}$-FEM and a multilevel mesh superposition method for the analysis of thick composite structures. Compos. Part B: Eng. 43(2): 559-568

[73] Aslami M and Akimov P A 2016 Wavelet-based finite element method for multilevel local plate analysis. ThinWalled Struct. 98: 392-402

[74] Zhang S and Cheng L 2017 Wavelet decompositions for high frequency vibrational analyses of plates. Int J. Appl. Mech. 9(06): 1750088

[75] Geng J, Zhang X, Chen X and Xue X 2016 High-frequency vibration analysis of thin plate based on B-spline wavelet on interval finite element method. ASME 2016 In: International Mechanical Engineering Congress and Exposition Phoenix, Arizona, USA V013T01A016-V013T01A016

[76] Mohite P M, Upadhyay C S 2006 Accurate computation of critical local quantities in composite laminated plates under transverse loading. Comput. Struct. 84: 657-675

[77] Theofanis S P, Saravanos D A 2009 Higher-order layerwise laminate theory for the prediction of interlaminar shear stresses in thick composite and sandwich composite plates Compos. Struct. 87: 23-35

[78] Maturi D A, Ferreira A.J.M, Zenkour A M and Mashat D S 2014 Analysis of sandwich plates with a new layerwise formulation. Compos. Part B-Eng. 56: 484-489

[79] Mashat D S, Carrera E, Zenkour A M, Al Khateeb S A 2014 Use of axiomatic/asymptotic approach to evaluate various refined theories for sandwich shells. Compos. Struct. 109: 139-149

[80] Cinefra M, Carrera E, Lamberti A and Petrolo M 2017 Best theory diagrams for multilayered plates considering multifield analysis. J. Intell. Mater. Syst. Struct. 1045389X16679018

[81] Mohite P M, Upadhyay CS 2007 Region-by-region modeling of laminated composite plates. Comput. Struct. 85: $1808-1827$

[82] Saeedi N, Sab K and Caron J F 2012 Delaminated multilayered plates under uniaxial extension. Part I: Analytical analysis using a layerwise stress approach. Int. J. Solids Struct. 49: 3711-3726

[83] Saeedi N, Sab K and Caron J F 2012 Delaminated multilayered plates under uniaxial extension. Part II: Efficient layerwise mesh strategy for the prediction of delamination onset. Int. J. Solids Struct. 49: 3727-3740

[84] Saeedi N, Sab K and Caron J F 2013 Cylindrical bending of multilayered plates with multi-delamination via a layerwise stress approach. Compos. Struct. 95: 728-739

[85] Sahoo R and Singh B N 2014 A new trigonometric zigzag theory for buckling and free vibration analysis of laminated composite and sandwich plates. Compos. Struct. 117: 316-332

[86] Theofanis S P and Papadopoulos E G 2015 Higher-order 2-D/3-D layerwise mechanics and finite elements for 
composite and sandwich composite plates with piezoelectric layers. Aerosp. Sci. Technol. 40: 150-163

[87] Moleiro F, Soares C M, Soares, C M and Reddy J N 2015 Layerwise mixed models for analysis of multilayered piezoelectric composite plates using least-squares formulation. Compos. Struct. 119: 134-149

[88] Timoshenko S and Goodier V N 1979 Theory of Elasticity (3rd edition), NewYork, NY: McGraw-Hill

[89] Durelli A J and Ranganayakamma B 1989 Parametric solution of stresses in beams. J. Eng. Mech. 115: 401-415

[90] Akanda M A S, Ahmed S R, Khan R M and Uddin M W 2000 A finite-difference scheme for mixed boundary value problems of arbitrary-shaped elastic bodies. Adv. Eng. Softw. 31: 173-184

[91] Nath S K D 2007 Displacement Potential Approach to Solution of Elasticity Problems of Orthotropic Composites Structures. Ph.D. Dissertation, Department of Mechanic Engineering, Bangladesh University of Engineering and Technology Dhaka, Bangladesh

[92] Deb Nath S K 2014 A finite difference solution of a simply supported beam of orthotropic composite materials using displacement potential formulation. Chin. J. Eng. 2014: 961503

[93] Deb Nath S K and Ahmed S R 2009 A displacement potential-based numerical solution for orthotropic composite panels under end moment and shear loading. $J$. Mech. Mater. Struct. 4: 987-1004

[94] Huq, N M L and Afsar A M 2012 A mathematical model for the analysis of elastic field in a stiffened cantilever of laminated composite. Adv. Mech. Eng. 4:170704

[95] Nath S K D, Afsar A M 2009 Analysis of the effect of fiber orientation on the elastic field in a stiffened orthotropic panel under uniform tension using displacement potential approach. Mech. Adv. Mater. Struct. 16: 300-307

[96] Nath, S K D, Ahmed S R and Afsar A M 2006 Displacement potential solution of short stiffened flat composite bars under axial loading. Int. J. Appl. Mech. Eng. 11: 557-575

[97] Afsar A M, Huq N M L and Song J I 2009 Displacement potential solution to elastic field in a stiffened cantilever of laminated composite. In: 17th International Conference on Composite Materials, Edinburgh, Scotland, July 27-31

[98] Nath S K D, Afsar A M and Ahmed S R 2007 Displacement potential solution of a deep stiffened cantilever beam of orthotropic composite material. J. Strain Anal. Eng. 42: 529-540

[99] Afsar A M, Deb Nath S K and Ahmed S R 2008 Displacement potential based finite difference solution to elastic field in a cantilever beam of orthotropic composite. Mech. Adv. Mater. Struct. 15: 386-399

[100] Koizumi M 1997 FGM activities in Japan. Compos. Part B-Eng. 28: 1-4

[101] Suresh S, Mortensen A 1998 Fundamentals of Functionally Graded Materials (1st edition), London: IOM Communications

[102] Praveen G N and Reddy J N 1998 Nonlinear transient thermoelastic analysis of functionally graded ceramic-metal plates. Int. J. Solids Struct. 35: 4457-4476

[103] Reddy J N 2000 Analysis of functionally graded plates. Int. J. Numer. Methods Eng. 47: 663-684
[104] Duc N D, Cong P H and Quang V D 2016 Nonlinear dynamic and vibration analysis of piezoelectric eccentrically stiffened FGM plates in thermal environment. Int. J Mech. Sci. 115: 711-722

[105] Zhang D G and Zhou H M 2015 Mechanical and thermal post-buckling analysis of FGM rectangular plates with various supported boundaries resting on nonlinear elastic foundations. Thin-Walled Struct. 89: 142-151

[106] Bateni M, Kiani Y, Eslami MR 2013 A comprehensive study on stability of FGM plates. Int. J Mech. Sci. 75: 134-144

[107] Abrate S 2006 Free vibration, buckling, and static deflections of functionally graded plates. Compos. Sci. Technol. 66: 2383-2394

[108] Abrate S 2008 Functionally graded plates behave like homogeneous plates. Compos. Part B- Eng. 39: 151-158

[109] Ferreira A J M, Roque C M C and Jorge R M N 2005 Analysis of composite plates by trigonometric shear deformation theory and multiquadrics. Comput. Struct. 83: 2225-2237

[110] Ferreira A J M, Roque C M C, Jorge R M N, Fasshauer G E and Batra R C 2007 Analysis of functionally graded plates by a robust meshless method. Mech. Adv. Mater. Struct. 14: 577-587

[111] Vel S S and Batra R C 2004 Three-dimensional exact solution for the vibration of functionally graded rectangular plates. J. Sound Vib. 272: 703-730

[112] Brischetto S. 2017 Exact three-dimensional static analysis of single-and multi-layered plates and shells. Compos. Part B: Eng. 119: 230-252

[113] Tran LV, Phung-Van P, Lee J, Wahab MA, Nguyen-Xuan H. 2016 Isogeometric analysis for nonlinear thermomechanical stability of functionally graded plates. Compos. Struct. 40: 655-667

[114] Jha D K, Kant T and Singh R K 2013 A critical review of recent research on functionally graded plates. Compos. Struct. 96: 833-849

[115] Srinivas S and Rao AK 1970 Bending, vibration and buckling of simply supported thick orthotropic plates and laminates Int. J. Solids Struct. 6: 1463-1481

[116] Pandya B N, Kant T 1988 Higher-order shear deformable theories for flexure of sandwich plates-finite element evaluations. Int. J. Solids Struct. 24: 1267-1286

[117] Pandya B N, Kant T 1988 Flexure analysis of laminated composites using refined higher-order Co plate bending elements. Comput. Methods Appl. Mech. Eng. 66: 173-198

[118] Pandya B N, Kant T 1988 Finite element stress analysis of laminated composite plates using higher order displacement model. Compos. Sci. Technol. 32: 137-155

[119] Zhang B, He Y, Liu D, Shen L and Lei J 2015 An efficient size-dependent plate theory for bending, buckling and free vibration analyses of functionally graded microplates resting on elastic foundation. Appl. Math. Model. 39(13): 3814-3845

[120] Thai H T and Choi D H 2011 A refined plate theory for functionally graded plates resting on elastic foundation. Compos. Sci. Technol. 71: 1850-1858

[121] Lam D C, Yang F, Chong A C, Wang J and Tong P 2003 Experiments and theory in strain gradient elasticity. $J$ Mech. Phys. Solids 51(8): 1477-1508 
[122] Belabed Z, Houari M S A, Tounsi A and Mahmoud S R 2014 An efficient and simple higher order shear and normal deformation theory for functionally graded material (FGM) plates. Compos. Part B-Eng. 60: 274-283

[123] Mantari J L and Soares C G 2013 A novel higher-order shear deformation theory with stretching effect for functionally graded plates. Compos. Part B-Eng. 45: 268-281

[124] Carrera E, Salvatore B and Alessandro R 2008 Variable kinematic model for the analysis of functionally graded material plates. AIAA J. 46: 194-203

[125] Stein M 1986 Nonlinear theory for plates and shells including the effects of transverse shearing. AIAA J. 24: $1537-1544$

[126] Zenkour A M 2007 Benchmark trigonometric and 3-D elasticity solutions for an exponentially graded thick rectangular plate. Arch. Appl. Mech. 77: 197-214

[127] Zenkour A M 2006 Generalized shear deformation theory for bending analysis of functionally graded plates. Appl. Math. Model. 30: 67-84

[128] Mantari J L and Soares C G 2012 Bending analysis of thick exponentially graded plates using a new trigonometric higher order shear deformation theory. Compos. Struct. 94: 1991-2000

[129] Mantari J L and Soares C G 2014 Four-unknown quasi-3D shear deformation theory for advanced composite plates. Compos. Struct. 109: 231-239

[130] Mantari J L 2015 A refined theory with stretching effect for the dynamics analysis of advanced composites on elastic foundation. Mech. Mater. 86: 31-43

[131] Gingold R A and Monaghan J.J 1977 Smoothed particle hydrodynamics: theory and application to non-spherical stars. Mon. Not. R. Astron. Soc. 181: 375-389

[132] Nayroles B, Touzot G and Villon P 1992 Generalizing the finite element method: diffuse approximation and diffuse elements. Comput. Mech. 10: 307-318

[133] Lancaster P and Salkauskas K 1981 Surfaces generated by moving least squares methods. Math. Comput. 37: 141-158

[134] Belytschko T, Lei G and Lu Y Y 1994 Fracture and crack growth by element free Galerkin methods. Model. Simul. Mater. Sci. Eng. 2: 519

[135] Belytschko T, Krongauz Y, Organ, D, Fleming M and Krysl P 1996 Meshless methods: an overview and recent developments. Comput. Meth. Appl. Mech. Eng. 139: 3-47

[136] Krysl P and Belytschko T 1995 Analysis of thin plates by the element-free Galerkin method. Comput. Mech. 17: 26-35

[137] Krysl P, Belytschko T 1996 Analysis of thin shells by the element-free Galerkin method. Int. J. Solids Struct. 33: 3057-3080

[138] Liu W K, Jun S and Zhang Y F 1995 Reproducing kernel particle methods. Int. J. Numer. Methods Fluids 20: 1081-1106

[139] Liu W K, Li S and Belytschko T 1997 Moving least-square reproducing kernel methods (I) methodology and convergence. Comput. Meth. Appl. Mech. Eng.. 143: 113-154

[140] Li S and Liu W K 1996 Moving least-square reproducing kernel method Part II: Fourier analysis. Comput. Meth. Appl. Mech. Eng. 139: 159-193

[141] Donning B M and Liu W K 1998 Meshless methods for shear-deformable beams and plates. Comput. Meth. Appl. Mech. Eng. 152: 47-71
[142] Li S, Hao W and Liu W K 2000 Numerical simulations of large deformation of thin shell structures using meshfree methods. Comput. Mech. 25: 102-116

[143] Liu G R 2009 Meshfree Methods: Moving Beyond the Finite Element Method. New York, NY: CRC Press

[144] Atluri S N and Zhu T 1998 A new meshless local PetrovGalerkin (MLPG) approach in computational mechanics. Comput. Mech. 22: 117-127

[145] Atluri S N and Zhu T L 2000 The meshless local PetrovGalerkin (MLPG) approach for solving problems in elastostatics. Comput. Mech. 25: 169-179

[146] Long S and Atluri S N 2002 A meshless local PetrovGalerkin method for solving the bending problem of a thin plate. Comput. Model. Eng. Sci. 3: 53-64

[147] Thai C H, Nguyen T N, Rabczuk T and Nguyen-Xuan H 2016 An improved moving Kriging meshfree method for plate analysis using a refined plate theory. Comput. Struct. 176: $34-49$

[148] Vaghefi R, Hematiyan M R and Nayebi A 2016 Threedimensional thermo-elastoplastic analysis of thick functionally graded plates using the meshless local PetrovGalerkin method. Eng. Anal. Bound. Elem. 71: 34-49

[149] Wu C P, Chiu K H and Wang YM 2011 RMVT-based meshless collocation and element-free Galerkin methods for the quasi-3D analysis of multilayered composite and FGM plates. Compos. Struct. 93: 923-943

[150] Singh J, Singh S and Shukla K K 2014, Meshless Analysis of Laminated Composite and Sandwich Plates Subjected to Various Types of Loads, Int. J. Comput. Methods Eng. Sci. Mech. 15: 158-171

[151] Sator L, Sladek V and Sladek J 2014 Coupling effects in elastic analysis of FGM composite plates by mesh-free methods. Compos. Struct. 115: 100-110

[152] Jalušić B, Sorić J, Jarak T. 2017 Mixed meshless local Petrov-Galerkin collocation method for modeling of material discontinuity. Comput. Mech. 59(1): 1-9

[153] Kaewumpai S and Luadsong A 2015 Two-field-variable meshless method based on moving kriging interpolation for solving simply supported thin plates under various loads. J. King Saud Univ. Sci. 27(3): 209-216

[154] Belinha J, Dinis LM, Jorge RN. 2013 Analysis of thick plates by the natural radial element method. Int. J Mech. Sci. 76: 33-48

[155] Zhu P and Liew K M 2011 Free vibration analysis of moderately thick functionally graded plates by local Kriging meshless method. Compos. Struct. 93: 2925-2944

[156] Zhu P and Liew K M 2012 A local Kriging meshless method for free vibration analysis of functionally graded circular plates in thermal environments. Procedia Eng. 31: 1089-1094

[157] Cui X, Liu G. and Li G 2011 A smoothed Hermite radial point interpolation method for thin plate analysis. Arch. Appl. Mech. 81: 1-18

[158] Zhao X, Lee Y Y and Liew K M 2009 Free vibration analysis of functionally graded plates using the elementfree kp-Ritz method. J. Sound Vib. 319: 918-939

[159] Zhang LW, Zhu P and Liew K. M 2014 Thermal buckling of functionally graded plates using a local Kriging meshless method. Compos. Struct. 108: 472-492

[160] Fantuzzi N, Bacciocchi M, Tornabene F, Viola E and Ferreira A J 2015 Radial basis functions based on 
differential quadrature method for the free vibration analysis of laminated composite arbitrarily shaped plates. Compos. Part B: Eng. 78: 65-78

[161] Bui T Q, Doan D H, Van Do T, Hirose S and Duc N D 2016 High frequency modes meshfree analysis of ReissnerMindlin plates. J. Sci. Adv. Mater. Dev. 1: 400-412

[162] Dey S, Naskar S, Mukhopadhyay T, Gohs U, Spickenheuer A, Bittrich L, Sriramula S, Adhikari S, Heinrich G 2016 Uncertain natural frequency analysis of composite plates including effect of noise-a polynomial neural network approach. Compos. Struct. 143: 130-142

[163] Mallela U K and Upadhyay A 2016 Buckling load prediction of laminated composite stiffened panels subjected to in-plane shear using artificial neural networks. Thin-Walled Struct. 102: 158-164

[164] Vosoughi A R, Darabi A, Anjabin N and Topal U 2017 A mixed finite element and improved genetic algorithm method for maximizing buckling load of stiffened laminated composite plates. Aerosp. Sci. Technol. 70: 378-387

[165] Fleming M, Chu YA, Moran B and Belytschko T 1997 Enriched element-free Galerkin methods for crack tip fields. Int. J. Numer. Methods Eng. 40: 1483-1504

[166] Lee SH and Yoon YC 2004 Numerical prediction of crack propagation by an enhanced element-free Galerkin method. Nucl. Eng. Des. 227: 257-271

[167] Li S and Liu WK 2002 Meshfree and particle methods and their applications. Appl. Mech. Rev. 55: 1-34

[168] Zhuang X, Augarde C E and Mathisen K M 2012 Fracture modeling using meshless methods and level sets in 3D: framework and modeling. Int. J. Numer. Methods Eng. 92: 969-998

[169] Khazal H, Bayesteh H, Mohammadi S, Ghorashi S S and Ahmed A 2016 An extended element free Galerkin method for fracture analysis of functionally graded materials. Mech. Adv. Mater. Struct. 23: 513-528

[170] Zhang Ch, Cui M, Wang J, Gao X W, Sladek J and Sladek V 2011 3D crack analysis in functionally graded materials. Eng. Fract. Mech. 78: 585-604

[171] Zhang CZ, Gao XW, Sladek J and Sladek V 2006 Fracture mechanics analysis of 2-D FGMs by a meshless BEM. Key Eng. Mater. 324: 1165-1172

[172] Gao XW, Guo L and Zhang C 2007 Three-step multi-domain BEM solver for nonhomogeneous material problems Eng. Anal. Bound. Elem. 31: 965-973

[173] Zhuang X, Cai Y and Augarde C 2014 A meshless subregion radial point interpolation method for accurate calculation of crack tip fields. Theor. Appl. Fract. Mech. 69: $118-125$

[174] Aslan Z and Şahin M 2009 Buckling behavior and compressive failure of composite laminates containing multiple large delaminations. Compos. Struct. 89: 382-390

[175] Liew KM, Zhao X, Ferreira AJ. 2011 A review of meshless methods for laminated and functionally graded plates and shells. Compos. Struct. 93(8): 2031-2041

[176] Macri M and De S 2009 A Partition of Unity-Based Multiscale Method. Progress on Meshless Methods. Dordrecht: Springer

[177] Ching L S and Hoe Y S 2014 Localized multiscale of 2D Burgers' equation with penalty using meshless approximation. In: Proceedings of the 21st National Symposium on Mathematical Sciences (SKSM21): Germination of Mathematical Sciences Education and Research towards Global Sustainability. 1605(58), Penang, Malaysia, November 6-8

[178] Shojaei A, Mudric T, Zaccariotto M and Galvanetto U 2016 A coupled meshless finite point/Peridynamic method for 2D dynamic fracture analysis. Int. J Mech. Sci. 119: 419-431 